\title{
Artificial Momentum, Native Contrarian, and Transparency in China
}

\author{
Hung-Wen Lin ${ }^{1}$ • Mao-Wei Hung² $•$ \\ Jing-Bo Huang ${ }^{3}$
}

\begin{abstract}
The Chinese stock market has a large ratio of retail investors, which is significantly different from the stock markets in the US and Europe. We have known that momentum profits exist in the latter by applying Jegadeesh and Titman's (J Financ 48:65-91, 1993) model with 6-month formation and holding periods. However, there are only a few studies on momentum profits in China. Therefore, this study examines whether the Shanghai and Shenzhen stock markets produce momentum profits. We find that these two markets have significant contrarian but not momentum profits. We also create an "artificial momentum" portfolio and follow Bhattacharya et al. (Account Rev $78: 641-678,2003)$ to compute the transparency indices. Our outcomes show that the corporate transparencies of the winners (losers) in the artificial momentum portfolios are close to those in the commonly-defined momentum portfolios. The averages of the decile transparencies are between 4.5 and 6.5, not only for the top $10 \%$ of winners but also for the bottom $10 \%$ of losers. According to these results, we suggest that financial transparency is irrelevant to the inertia and reversal of stock prices in the Shanghai and Shenzhen stock markets.
\end{abstract}

Keywords Momentum · Transparency · Contrarian

JEL Classification G11 $\cdot$ G18 $\cdot$ G32

\footnotetext{
$凶 \quad$ Hung-Wen Lin pm4@nccu.edu.tw

1 Nanfang College of Sun Yat-Sen University, No. 882, Wenquan Rd., Conghua, Guangzhou, China

2 International Business, National Taiwan University, No. 1, Sec. 4, Roosevelt Rd., Taipei, Taiwan

3 Lingnan College, Sun Yat-Sen University, No. 135, Xingang Xi Rd., Guangzhou, China
} 


\section{Introduction}

Chinese stock markets differ from the US and European markets in several ways. For example, China's stock markets have a backdoor listing, and the main participants in these markets are retail investors instead of investment banks. Intuitively, the unique market structure may be characterized by different phenomena and investment strategies. Institutional investors have more inside information and the ability to understand corporations' operating statements. Therefore, their investment strategies are stable as observed in US stock markets. On the contrary, retail investors usually do not have enough knowledge to have a good understanding of the corporate information. Besides, according to Kang et al. (2002), the information reported by small companies in China's stock markets is not reliable. Rumors and investor sentiment can easily be manipulated by syndicate speculators. Su (2011) even pointed out that market manipulation is pivotal in explaining the industry momentum profits in Chinese stock markets. Rumors significantly affect the volatility of China's stock prices, and transparency is a serious problem in China's financial markets. Therefore, an inertia strategy is not suitable for investors in China's stock markets.

Previous research has found that the US stock markets respond to information gradually. Chan et al. (1996) pointed out that the prices of stocks with the worst past performance respond sluggishly to past news. Hong et al. (2000) identified that (a) there is a concave relationship between momentum profit and firm size; (b) a momentum strategy is more profitable when firm-specific information moves more slowly; and (c) the effect of analyst coverage is larger on past losers than winners.

Recently, many listed companies in China have abandoned the traditional business models and adopted a modern accounting system that uses earnings management to manipulate financial statements and the companies' transparency, which draws our attention to the impact of corporate transparency on stock prices in China. We use three indices of earnings management in the transparency model developed by Bhattacharya et al. (2003) to measure the transparency of a listed company. We suspect that uncertainty caused by low transparency leads to a reversal of stock prices, since true news ferments and takes effect slowly. Before investors have access to accurate information, they can only refer to rumors; portfolios may also be affected by their sentiments (Kang et al. 2002).

Manipulations and speculations exist in the Shenzhen and Shanghai stock markets, as is well known by most local investors. Spreading rumors and using insider information generate excess returns and directly trigger fluctuations in stock prices (Kang et al. 2002). The exposure of true information may give rise to a reversion in stock prices and make momentum profits disappear. Speculation games are staged every trading day. Although it is important to know whether contrarian profits dominate in China's stock markets because of the globalization trend of international capital, only a few studies on momentum profits include samples from the Asia-Pacific (e.g., Fama and French 2012; Griffin et al. 2003; Chui et al. 2010).

In 1992, the Chinese government grouped stocks into two categories, A-shares and B-shares, to reduce shocks from foreign capital markets to its developing finance systems. The HKD must be used to trade B shares on the Shenzhen Stock Exchange, and the USD on the Shanghai Stock Exchange. Because China's forex market is still 
controlled by the government, there is a liquidity problem with B shares. Since more and more global capital flows into China's stock markets and liquidity is always an important research topic, we must survey the difference in liquidity between A-shares and B-shares and find the special patterns, if any, in the Shenzhen and Shanghai stock markets.

Fama and French (2012) and Asness et al. (2013) analyzed the relationships between value (book-to-market) and momentum strategy across different markets. Asness et al. (2013) used data on country equity index futures, government bonds, currencies, commodity futures, and individual stocks in the USA, UK, continental Europe, and Japan, but, unfortunately, their research did not provide a detailed discussion on China's stock market. Consequently, we have an incentive to investigate the strategies used in this large market.

Chordia and Shivakumar (2002) showed that momentum profits, explained by a set of lagged macroeconomic factors, disappear once stock returns are adjusted for their predictability based on these macroeconomic factors. Returns to momentum portfolios are positive only during expansion periods and become negative during recession periods. Cooper et al. (2004) examined overreaction theories in the cross section of stock returns and found a correlation between momentum profits and market status. One of their conclusions was that the 6-month momentum strategy generates an average monthly profit of $0.93 \%$ after 3 -year UP markets and an average monthly profit of $-0.37 \%$ after 3 -year DOWN markets. They also found that macroeconomic elements cannot explain this profitability even with methodological adjustments to accommodate microstructure concerns. Instead, they believe that the business cycle is one factor that affects momentum profitability.

The literature discussed in this paper focuses on determining which macroeconomic factors influence momentum profits. However, the revenue continuity (predictability) could have many connections with the individual corporation's features. Moskowitz and Grinblatt (1999) showed that industry momentum investment strategies that buy stocks from past winning industries and sell stocks from past losing industries appear to be highly profitable, even after controlling for size, book-to-market equity, individual stock momentum, the cross-sectional dispersion in mean returns, and potential microstructure influences. If an individually observable variable that significantly affects momentum strategy exists, then we can use this proxy to assess and forecast the continuity of profit of a single corporation. The transparency index designed by Bhattacharya et al. (2003) is an idiosyncratic and computable variable after financial announcements. We believe that an ex-ante proxy will make it easy for us to evaluate the predictability (continuity) of profit.

Asian economies have rapidly developed in the past ten years. Although the sizes of China's stock markets cannot compare with those of the US stock markets, we cannot ignore China's stock markets in global finance. While there are abundant studies on momentum strategies in various developed countries, little attention has been paid to the momentum strategies in Chinese stock markets. One of the reasons is that the data on corporations in China contain biases and errors. Another reason is that information about corporations is incomplete. However, the data have been progressively corrected, and the published stock prices are accurate. 
Therefore, we investigate the Shanghai and Shenzhen Stock Exchanges by analyzing the published stock prices. There are four distinctive features of our research. First, we use a technology that differs from that used in the literature to detect the coexistence of contrarian and momentum profits in stock markets, given the same holding and formation periods. Second, we combine Shanghai B-shares with Shenzhen B-shares to discuss the momentum profits of non-RMB investors, which is a novel design as yet not seen in past studies (e.g., Jiang 2012; Wu 2011; Kang et al. 2002; Chui et al. 2010; Su 2011). This design also renders the analysis of momentum profits in China's stock markets more complete and robust. Third, the maximum length of our formation and holding periods is 36 months for nine different subsample markets. Finally, we examine corporate transparency to expose the existence of false financial reports, which corresponds to the study of false news and rumors in Kang et al. (2002).

Under the traditional method in Jegadeesh and Titman (1993), the momentum return could be either "positive" or "negative". In practice, a retail investor can only have a subset of the portfolio identified by using the traditional momentum strategy. This portfolio could bring a return to the investor that differs from the outcome calculated under the traditional definition. Our two-step method allows us to detect these two types of returns simultaneously. In the first step, we will find a "positive" or "negative" momentum return under the traditional definition. In the second step, we will find the other type of return not found in the first step. These two steps enable us to study momentum and contrarian returns in any stock market simultaneously.

The remainder of this paper is organized as follows: Section 2 describes our research logic and methodology to study momentum profits. We also construct an "artificial momentum profit" and compute transparency indices. Section 3 shows the momentum profits in different types of Chinese stock markets, and we also provide possible explanations for investor behavior in the Shanghai and Shenzhen stock markets. In Sect. 4, we discuss the role of transparency in China's stock markets and provide empirical evidence. Section 5 concludes this study.

\section{Models and Data Descriptions}

The momentum effect is often calculated in the literature by assuming a 6-month formation period and a 6-month holding period. Many studies find that momentum profits turn from positive to negative when the holding period is extended (e.g., Hillert et al. 2014; Chui et al. 2010; Cooper et al. 2004; Griffin et al. 2003; Chan et al. 1996; Jegadeesh and Titman 1993). To test whether China's stock markets also exhibit the phenomenon of profit reversal, we conduct our analysis by assuming that the holding period ranges from 1 to 36 months.

\subsection{Momentum Computation}

Barucci et al. (2004) argued that the past performance of a stock (short memory) in the forecasting rule (learning process) induces long-range dependencies in the time series. If agents change their prediction rules according to the past performance of the stock, then there is a fluctuation in the financial market (overreaction or delayed overreaction). 
We take this overreaction into consideration to construct our standardized model as follows.

Suppose that a sample period has $Q$ months, where $Q \geq f+l+H, f$ is the number of months in the formation period, $l$ is the number of months in the lagged period, and $H$ is the number of months in the longest holding period. We focus on the stocks whose data are complete during the $(f+l+h)$ month period, where $h$ is the number of months in the holding period. ${ }^{1}$ During the $f$-month formation period of portfolio $i$, we use the yield $\Delta P_{i, t}=\frac{\overline{P_{f}}-\overline{P_{1}}}{\overline{P_{1}}}\left(\overline{P_{f}}\right.$ and $\overline{P_{1}}$ are the average stock prices in the $f$ month and the first month of the formation period, respectively) to measure the stock return performance. Then, we rank $\Delta P_{i, t}$ to choose the top $n_{i, t} k$ and bottom $n_{i, t} k$ stocks as the winners and losers, respectively, where $k$ is the momentum ratio.

During the $l$-month time lag, we assume that investors buy the $n_{i, t} k$ winners and sell the $n_{i, t} k$ losers in the investing Portfolio $i \in N$ (there is a total of $Q-f-l-h+1$ portfolios in our sample, $N=\{1, \ldots Q-f-l-H+1\})$. We assume that investors hold Portfolio $i$ for $h$ months ( $h \leq H$, and the longest holding period is $H$ months). After the investors trade Portfolio $i$ in the $h$ th month, the momentum profit of Portfolio $i$ is $M P_{h}^{i, t}=\overline{W_{h}^{i, t}}-\overline{L_{h}^{i, t}}$, and the average of the winner's return during the $h$-month holding period is $\overline{W_{h}^{i, t}}=\frac{1}{n_{i, t} k} \sum_{s=1}^{n_{i, t} k} w_{s, h}^{i, t}$, where $w_{s, h}^{i, t}$ denotes the profit of winner $s$ in Portfolio $i$ during the $h$-month holding period. ${ }^{2}$ The average of the loser returns during the $h$-month holding period is $\overline{L_{h}^{i, t}}=\frac{1}{n_{i, t} k} \sum_{q=1}^{n_{i, t} k} l_{q, h}^{i, t}$, where $l_{q, h}^{i, t}$ denotes the profit of loser $q$ in Portfolio $i$ during the $h$-month holding period. ${ }^{3}$

As discussed above, we have $Q-f-l-h+1$ portfolios. Hence we can obtain the following momentum profit structure:

$M P \equiv\left(\begin{array}{cccc}M P_{2}^{1,\left[t_{1}, T_{1}\right]} & \cdots & M P_{H}^{1,\left[t_{1}, T_{1}\right]} \\ M P_{1}^{1,\left[t_{1}, T_{1}\right]} & M P_{2}^{2,\left[t_{2}, T_{2}\right]} & \cdots & M P_{H}^{2,\left[t_{2}, T_{2}\right]} \\ M P_{1}^{2,\left[t_{2}, T_{2}\right]} & \vdots & \vdots & \vdots \\ \vdots & \vdots & \cdots & \vdots \\ M P_{1}^{Q-f-l-H+1,\left[t_{Q-f-l-H+1}, T_{Q-f-l-H+1}\right]} M P_{2}^{Q-f-l-H+1,\left[t_{Q-f-l-H+1}, T_{Q-f-l-H+1}\right]} & \cdots & M P_{H}^{Q-f-l-H+1,\left[t_{Q}-f-l-H+1, T_{Q-f-l-H+1}\right]}\end{array}\right)$

where the $\left[t_{1}, T_{Q-f-l-H+1}\right]$ amounts to $Q$ months, the total length of our sample period, so we can acquire the average $M P$ set via our portfolio profit set. The process is as follows:

$$
\left\{\overline{M P_{h}}\right\}_{1 \times H} \text {, where } \overline{M P_{h}}=\frac{1}{Q-f-l-H+1} \sum_{i=1}^{Q-f-l-H+1} M P_{h}^{i,\left[t_{i}, T_{i}\right]}
$$

\footnotetext{
1 There is a one-to-one correspondence between the $i$ and the $t$. The symbol $i$ refers to one portfolio while $t$ refers to one time pair $\left[t_{i}, T_{i}\right]$ where $t_{i}$ is the starting point of Portfolio $i$ 's formation period, and $T_{i}$ is the ending point of Portfolio $i$ 's longest holding period.

2 We use the average stock price $\overline{p_{s, l}^{i, t}}$ during the time lag as the entry price of winner $s$. By trading Portfolio $i$ in the $h$ month during the holding period, the profit gained by winner $s, w_{s, h}^{i, t}$, is calculated as $\overline{p_{s, h}^{i, t}}-\overline{p_{s, l}^{i, t}}$.

3 The profit of loser $q, l_{q, h}^{i, t}$, is calculated as $\overline{p_{q, h}^{i, t}}-\overline{p_{q, l}^{i, t}}$.
} 

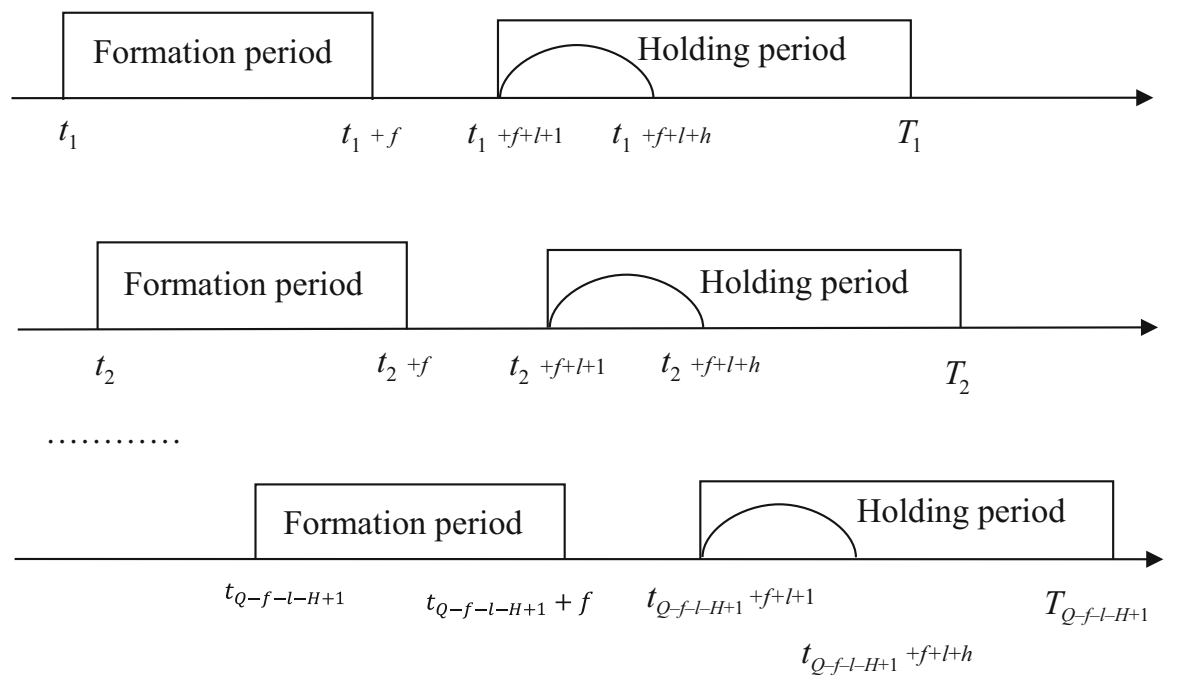

Fig. 1 Computational process of momentum profit

Therefore, we can obtain the momentum profit set $\overline{M P}=\left\{\overline{M P_{1}}, \overline{M P_{2}} \ldots \overline{M P_{H}}\right\}$ and graph the $\overline{M P}$ in Fig. 1 in which the horizontal line is the " $h$ " time.

\subsection{Artificial Winners and Losers}

We propose a general analysis of momentum profit. If researchers follow the original definition of momentum profit in previous studies (e.g., Jegadeesh and Titman 1993; Moskowitz and Grinblatt 1999; Lee and Swaminathan 2000; Chordia and Shivakumar 2002; Cooper et al. 2004; Avramov et al. 2007; Asness et al. 2013; Garlappi and Yan 2011; Hillert et al. 2014), they will find that not all winner-prices rise continuously in holding periods in China's stock markets. In addition, many prices of the losers increase in the holding periods. Therefore, we select the winner shares whose prices rise and call them "artificial winners." We also select the loser shares whose prices decline in the holding periods and call them "artificial losers". These winner and loser shares will produce an "artificial momentum profit".

By adopting Jegadeesh and Titman (1993)'s definitions, we receive only the contrarian profit when analyzing the data for Shenzhen's and Shanghai's data. We refer to such a contrarian profit as "native contrarian profit". That is, we can only study the relationship between the contrarian profit and transparency, and not the correlation between the momentum profit and transparency by using our dataset. With both native contrarian profit and artificial momentum profit, we can not only investigate price reversal but also discuss price inertia.

Our research compares the transparency indices between the momentum and contrarian strategies. A guess is that a high transparency share should have relatively complete information and increase the continuity of its price adjustment (either continually rising or falling). We also suspect that the diffusion of true information makes 
the probability of price reversal low and thus promotes the occurrence of momentum profit.

\subsection{Subsample Combinations}

We follow Lin et al. (2015) to analyze nine subsamples: (a) Shanghai A-shares, (b) Shenzhen A-shares, (c) Shanghai B-shares, (d) Shenzhen B-shares, (e) a combination of both the Shanghai and Shenzhen stock markets, (f) a combination of A-shares from the Shanghai and Shenzhen stock markets, (g) a combination of B-shares from the Shanghai and Shenzhen stock markets, (h) the Shanghai stock market, and (i) the Shenzhen stock market. We calculate the profits of momentum strategies in each of these nine subsamples and examine whether there are evidences of negative momentum profits.

In general, a stock market uses only one local currency. However, the traders have to use foreign currency in the Shenzhen and Shanghai B-share markets. To study "non-RMB-B-share" and RMB-A-share markets in China and compare the findings with the findings in the literature on momentum strategy, we test whether there are momentum profits in Shanghai B-shares, Shenzhen B-shares and the combination of B-shares in the Shanghai and Shenzhen stock markets.

\subsection{Data Description}

Our Shanghai and Shenzhen samples are collected from COMPUSTAT and the China Stock Markets and Accounting Research Database (CSMAR). The data period extends from January 2004 to April 2015. We rank the stocks in deciles according to their return rates during the formation period. The winner shares are the top $10 \%$ shares, and the loser shares the bottom $10 \%$. We calculate the momentum profit at the end of the holding period, and we weigh each stock equally in our calculation. We refer to Naughton et al. (2008) and adopt the raw return in the above calculation.

The data used to calculate transparency are all from CSMAR and China Infobank database. The data are on a monthly basis, and the data period is from December 2006 to March 2012. It contains both A-share stocks and B-share stocks in China's stock markets. We drop the stocks whose transparency data is incomplete. In the calculation of the transparency index, the lengths of the holding period and the formation period are both 6 months. Cooper et al. (2004) excluded stocks below $\$ 1$ at the end of the formation period, but in this research, we do not. Since only the Shanghai B-share market uses the USD to trade, it does not have a standard RMB price threshold as the A-share market.

\section{Experiment on Momentum Profits}

So far, few studies have provided a full discussion and analysis of the momentum strategies in the Shanghai-Shenzhen stock market, which is the second largest market 


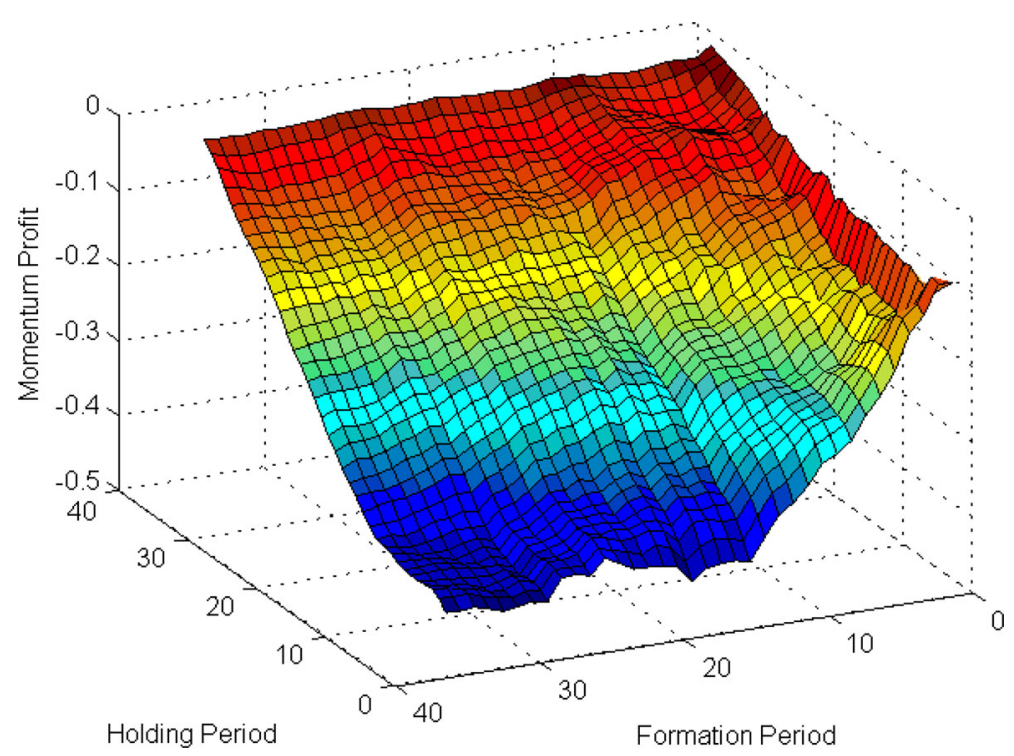

Fig. 2 Momentum profits of the Shanghai A-share market in 2 dimensions with formation and holding periods of $36 \times 36$ months

in the world. We would like to investigate the momentum strategies in China's stock markets and compare the results with those in the other main stock markets.

By referring to Jegadeesh and Titman (1993), we extend the formation period (1 to 36 months) to see if the market exhibits a price reversal. We analyze all possible cases in our dataset to ensure the accuracy of our results. Below are the five figures showing the momentum profits and their $t$-values during the $h \times h$ months of formation and holding period with $h=1,2, \ldots, 36$. All other cases appear in "Appendix A".

\section{a. Shanghai A-share market}

Our tests are different from most other research because our tests contain a 1- to 36-month formation period. This design increases the accuracy of our results. We use graphs to show the momentum profits with 36 formation periods and 36 holding periods. In line with the literature on momentum profits, this research adopts $t$ tests to analyze momentum profits (Figs. 2, 3). ${ }^{4}$

Given a holding period and a formation period, we have $Q-f-l-h+1$ portfolios (windows), and each one has a mean momentum profit. The sample size is the number of portfolios. We use a $t$-statistic to test whether the mean profit is different from zero. There is a negative momentum profit in the Shanghai and Shenzhen stock markets, and their $t$ statistics are almost lower than -2 . Therefore, we have significant evidence to show that these two markets suffered from price reversals.

\footnotetext{
4 For example, Jegadeesh and Titman (1993), Moskowitz and Grinblatt (1999), Lee and Swaminathan (2000), Chordia and Shivakumar (2002), Cooper et al. (2004), Avramov et al. (2007), Asness et al. (2013), Garlappi and Yan (2011), and Hillert et al. (2014).
} 


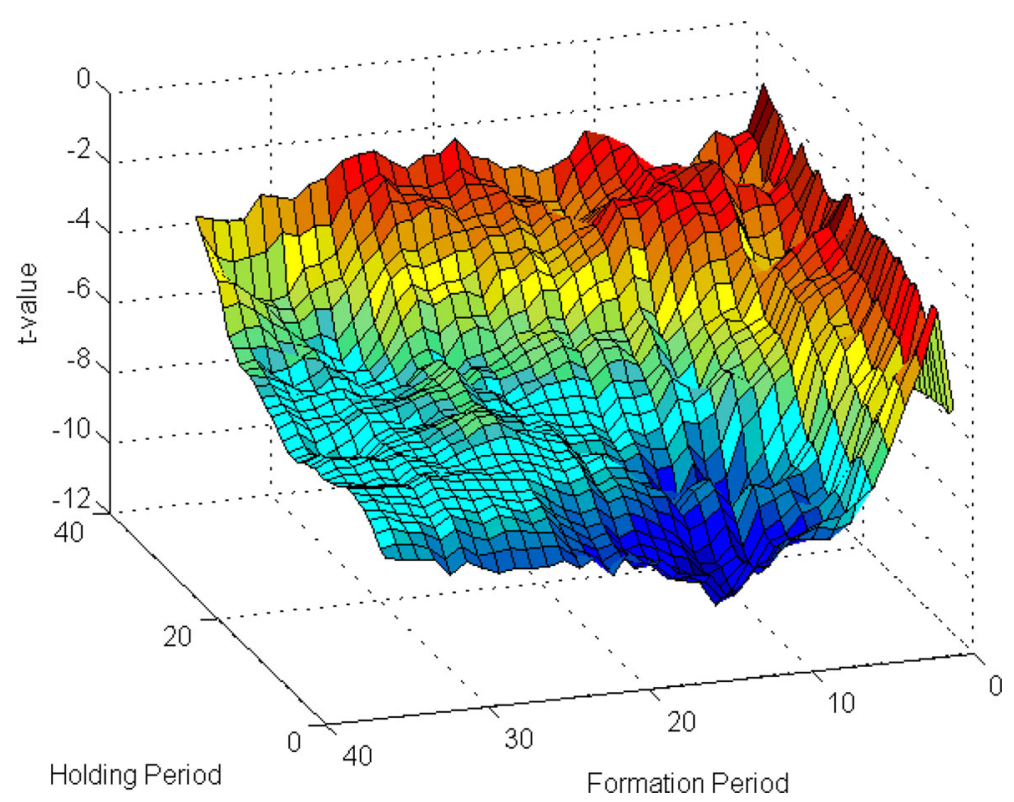

Fig. 3 Student $t$ values of the momentum profits in the Shanghai A-share market with formation and holding periods of $36 \times 36$ months

\section{b. Shenzhen A-share market}

After observing Figs. 4 and 5, we infer that the A-share market exhibit contrarian profits. Given the formation period, the profit decreases when the holding period is extended. In addition, the closer the length of the holding period to 36 months, the smaller the profits.

\section{c. Shanghai B-shares}

Except when there is a shorter holding period, most momentum strategies yield a negative profit. These outcomes are similar to those for the above tests. The maximum B-share contrarian profit occurs near $f=10$ and is smaller than that for A-shares in the Shanghai stock market.

Jiang (2012) collected weekly stock returns from January 1993 to December 2013 and considered that there was an insignificant momentum strategy for Shanghai Ashares within the very short run. Using daily data for the Chinese stock market from 1990 to 2001, Wu (2011) also found that the momentum profits are weak. In referring to Jiang and Bao (2015), we find that monthly momentum profits without risk management are not positive in the Shanghai stock market (see Figs. 2 and 6). On the basis of the above literature review and our own findings, we conclude that the positive momentum profit in this market is not obvious (Fig. 7).

\section{d. Shenzhen B-shares}

In Fig. 8, a few momentum profits are positive just at $f=1$ (a 1-month formation period). Their $t$-values are greater than 2 in Fig. 9, and there exists a significant 


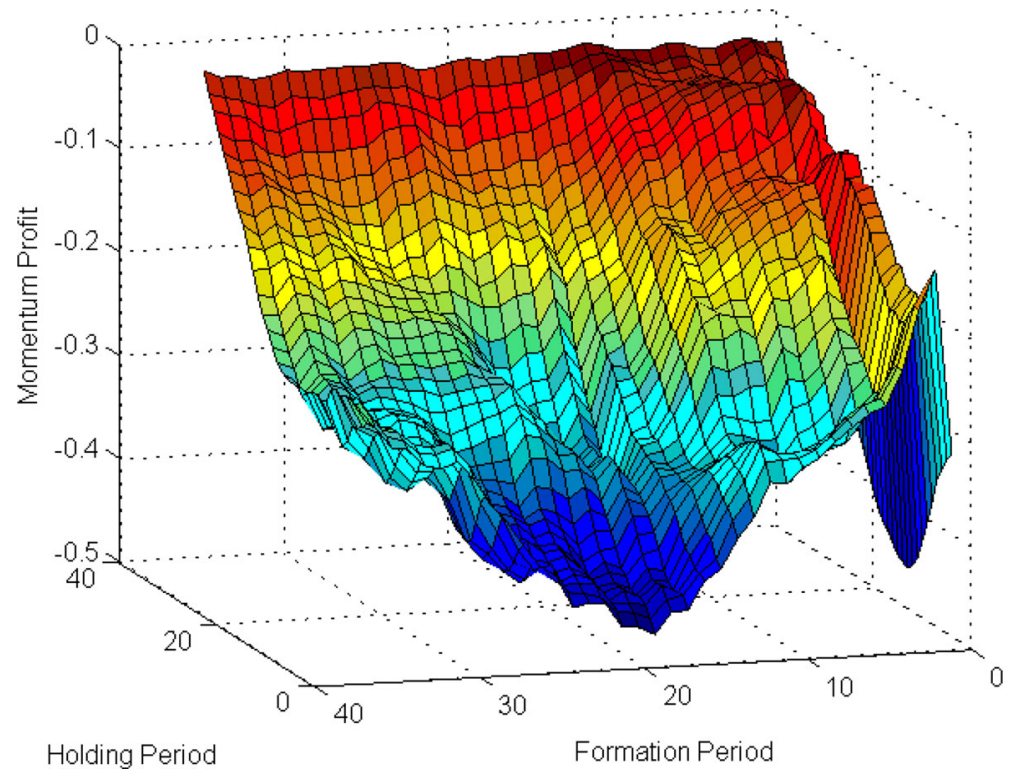

Fig. 4 Momentum profits of the Shenzhen A-share market in 2 dimensions with formation and holding periods of $36 \times 36$ months



Fig. 5 Student $t$ values of momentum profits in the Shenzhen A-share market in 2 dimensions with formation and holding periods of $36 \times 36$ months 


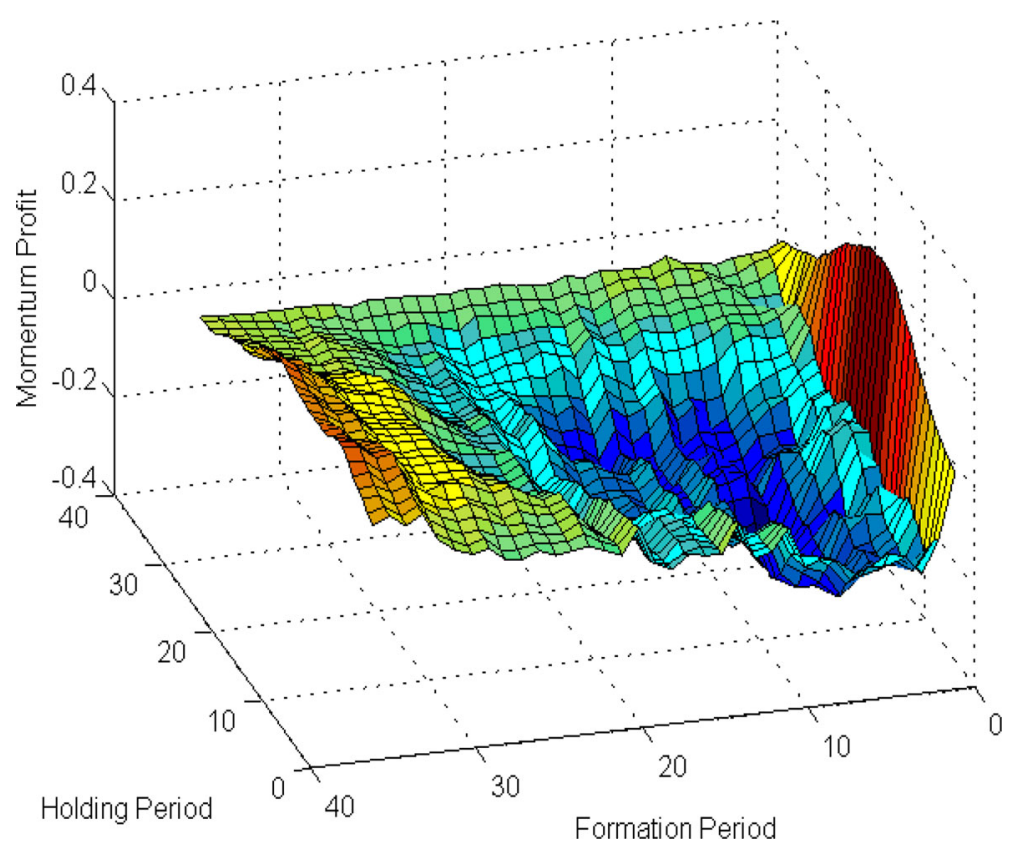

Fig. 6 Momentum profits of the Shanghai B-share market in 2 dimensions with formation and holding periods of $36 \times 36$ months

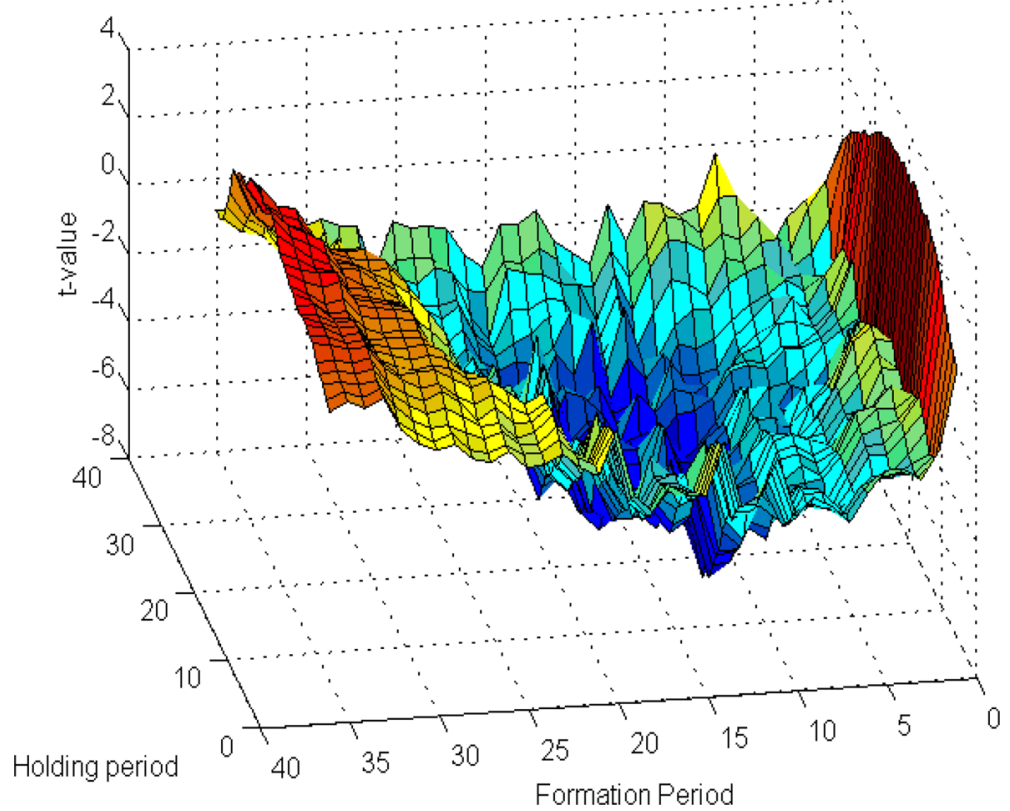

Fig. 7 Student $t$ values of the momentum profits for the Shanghai B-share markets in 2 dimensions with formation and holding periods of $36 \times 36$ months 


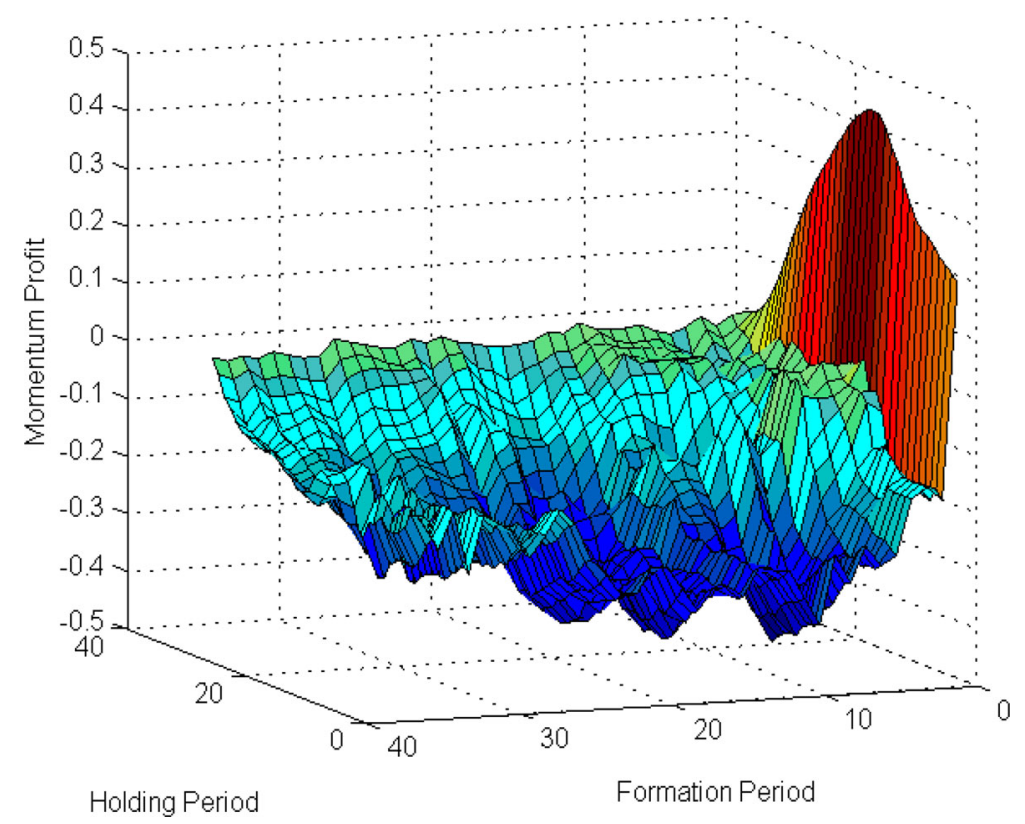

Fig. 8 Momentum profits of the Shenzhen B-share market in 2 dimensions with formation and holding periods of $36 \times 36$ months

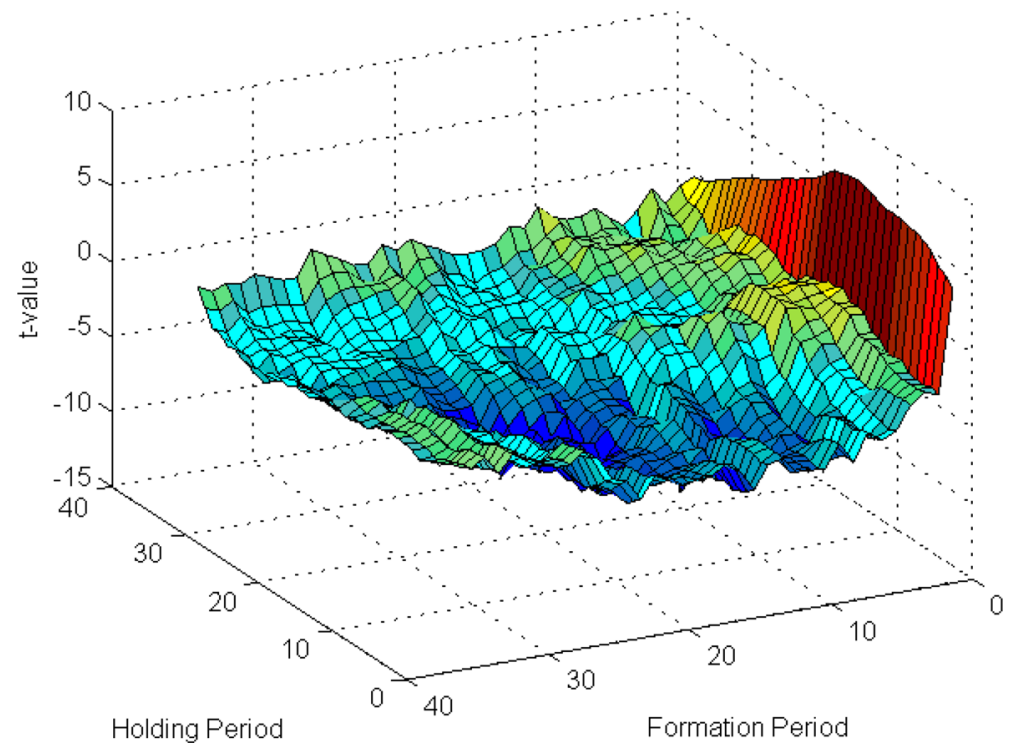

Fig. 9 Student $t$ values of momentum profits for the Shenzhen B-share market in 2 dimensions with formation and holding periods of $36 \times 36$ months 
momentum profit if $h<30$. Most contrarian strategies in this setting yield a substantial profit. Therefore, we can also roughly infer that price reversal occurs in the Shenzhen B-share market.

We know that the winner and loser shares under $f=1$ are different from those in cases under $f \geq 2$. A common phenomenon in both $\mathrm{B}$-share markets is that there exist momentum profits with a one-month formation period. The market structure may cause these profits. In fact, there are more institutional investors in the B-share market than in the A-share market. These investors are usually investment banks or market makers. They help many companies issue new shares, have access to insider information, and have a better ability to assess rumors.

\section{e. A fully combined market}

We have already discussed the contrarian profits in the Shanghai and Shenzhen stock markets. Our tests have also found that the combined Shanghai-Shenzhen stock market reveals the existence of a significant and stable contrarian profit. ${ }^{5}$

Naughton et al. (2008) found evidence of a strong momentum profit around the time of earnings announcements in the Shanghai stock market, which is different from our contrarian outcome. One of the reasons may be that their sample period is different from ours. The compositions of stocks will thus differ in different sample periods. Additionally, we do not specifically consider the timing of earnings announcements when calculating the momentum profits.

Figures 10 and 11 suggest that under the 6-month formation period, most winner shares saw their prices decline and most loser shares saw their prices rise in the holding period in the overall China stock market. The overall China stock market exhibits a contrarian return, while the US stock market shows a momentum return. In order to verify our conclusion, we have adopted different formation periods to determine the winner and loser shares. The tests all confirm the contrarian returns. To sum up, the contrarian profits are robust under $36 \times 36$ formation and holding periods (see all of the figures in this section).

\section{Transparency of Artificial Momentum and Native Contrarian}

According to the above analysis, we clearly show that China's stock markets favor the contrarian strategy, which is significantly different from the momentum strategies used in the US and European stock markets. Knowing the reason for this difference is important, and we suspect that the reason is that the degree of transparency in each of these markets is different. In general, the corporate financial reports in the developed regions have higher transparency. It has been found that transparency and momentum profits in the US and European stock markets are positively correlated. This section answers the question of whether the lower transparency of Chinese corporations affects the contrarian profits.

5 To streamline our article, we place the analysis of (f) combinations of A-shares in the Shanghai and Shenzhen stock markets, (g) combinations of B-shares in the Shanghai and Shenzhen stock markets, (h) the Shanghai stock market, and (i) the Shenzhen stock market in "Appendix A". 


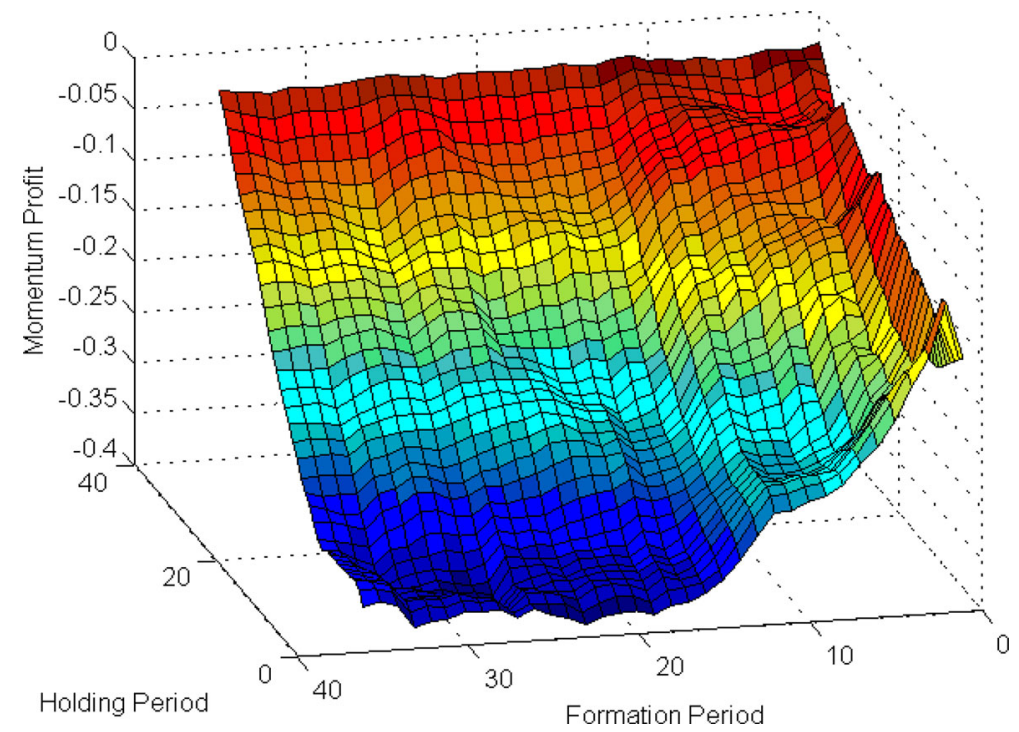

Fig. 10 Momentum profits of Shanghai-Shenzhen stock markets in 2 dimensions with formation and holding periods of $36 \times 36$ months

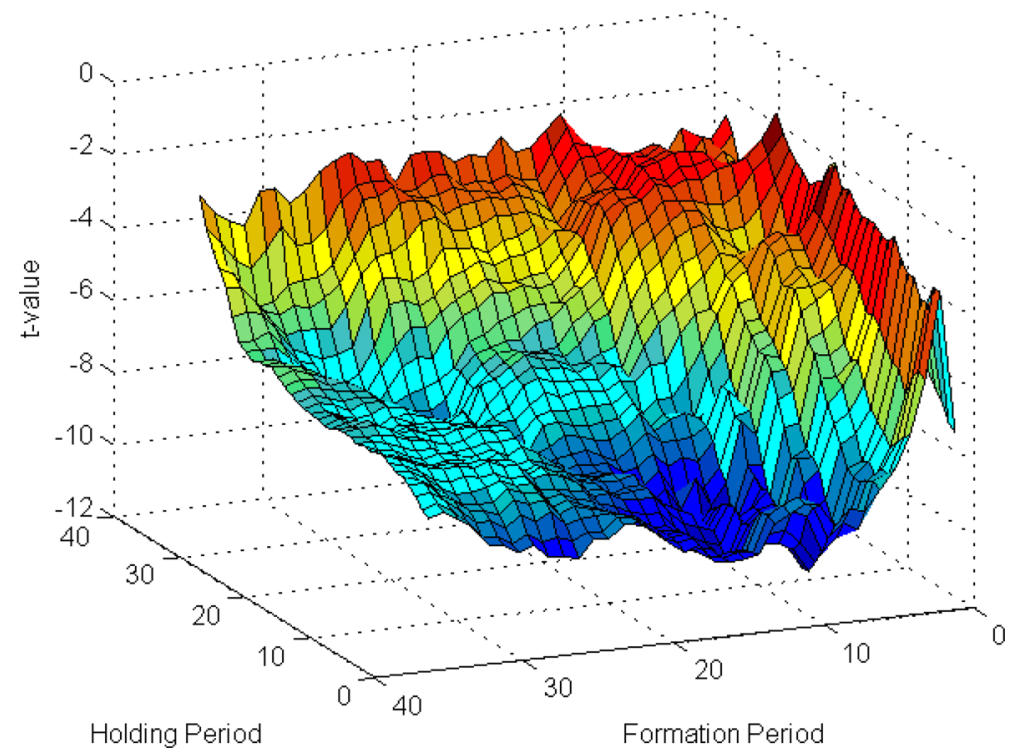

Fig. 11 Student $t$ values of the momentum profits in the Shanghai-Shenzhen stock markets in 2 dimensions with formation and holding periods of $36 \times 36$ months

\subsection{Distribution of Winners and Losers}

A price reversal occurred at $h=6$ according to the previous analysis, which means that the price inertias are broken by the updated expectations of investors after the 
formation period. In the period $t_{i}+f+l$, the winners and losers are determined. A price reversal means that "the same" winners had a loss and losers had profits in the period $t_{i}+f+l+h$. That is, most of the shares chosen in the original portfolios have changed their price trend in holding period $f$.

Now, we focus on the shares that belong to the original portfolios to see if they maintain their price trends. Some shares are selected to form an artificial momentum portfolio. Table 1 shows the numbers of winners and losers in the native contrarian portfolios and the artificial momentum portfolios.

To compare the degrees of transparency between the contrarian portfolios and momentum portfolios, we require that transparency indices be computed for every share in this table. In other words, the shares that have missing data are not included in this table. There are 84 portfolios in our sample.

\subsection{Methodology of Transparency}

From the above outcomes, we are sure that the Shenzhen-Shanghai stock market has contrarian profits, which is different from the situations in the US and European stock markets. Next, we try to discover the causes of the overreaction in the Shanghai stock market.

We follow Bhattacharya et al. (2003) to calculate the transparency of every listed corporation and use just two indices, Earnings Aggressiveness (EA) and Earnings Smoothing (ES), to measure their transparency. We compute the means of these indices and distribute them in deciles.

$$
\begin{aligned}
\mathrm{EA}_{\mathrm{it}} & =\mathrm{DA}_{\mathrm{it}}=\mathrm{TA}_{\mathrm{it}} / \overline{\mathrm{A}}_{\mathrm{it}}-\mathrm{NDA}_{\mathrm{it}} \\
\mathrm{ES}_{\mathrm{it}} & =\operatorname{Correl}\left(\Delta \mathrm{AC}_{\mathrm{it}}, \Delta \mathrm{CF}_{\mathrm{it}}\right) \\
\operatorname{Transp}_{\mathrm{it}} & =\frac{\operatorname{Deciles}\left(\mathrm{EA}_{\mathrm{it}}\right)+\operatorname{Deciles}\left(\mathrm{ES}_{\mathrm{it}}\right)}{2},
\end{aligned}
$$

where $\mathrm{DA}_{\mathrm{it}}$ is the discretionary accruals; $\mathrm{TA}_{\mathrm{it}}$ is total accrued profit before the items below the line, $\mathrm{TA}_{\mathrm{it}}=\mathrm{EBXI}_{\mathrm{it}}-\mathrm{CFO}_{\mathrm{it}}$; $\mathrm{EBXI}_{\mathrm{it}}$ is the earnings before interest and tax; $\mathrm{CFO}_{i t}$ is the cash flow from operations; $\overline{\mathrm{A}}_{\mathrm{it}}$ is the average value of the beginning and ending total assets; $\mathrm{NDA}_{i t}$ is the non-discretionary accruals stemming from the modified Jones model ${ }^{6} ; \Delta \mathrm{AC}_{\mathrm{it}}$ is the operating increase in accrued items; and $\Delta \mathrm{CF}_{\text {it }}$ is the operating net increase in cash flow.

6 The modified Jones model is: $\mathrm{NDA}_{\mathrm{it}}=\widehat{\alpha}_{11}\left(\frac{1}{\mathrm{~A}_{\mathrm{it}-1}}\right)+\widehat{\alpha_{12}}\left(\frac{\Delta \mathrm{REV}_{\mathrm{it}}-\Delta \mathrm{REC}_{\mathrm{it}}}{\mathrm{A}_{\mathrm{it}-1}}\right)+\widehat{\alpha_{13}}\left(\frac{\mathrm{PPE}_{\mathrm{it}}}{\mathrm{A}_{\mathrm{it}-1}}\right)$. The $\alpha$ coefficients are obtained from $\frac{\mathrm{TA}_{\mathrm{it}}}{\mathrm{A}_{\mathrm{it}-1}}=\alpha_{\mathrm{i} 1}\left(\frac{1}{\mathrm{~A}_{\mathrm{it}-1}}\right)+\alpha_{\mathrm{i} 2}\left(\frac{\Delta \mathrm{REV}_{\mathrm{it}}}{\mathrm{A}_{\mathrm{it}-1}}\right)+\alpha_{\mathrm{i} 3}\left(\frac{\mathrm{PPE}_{\mathrm{it}}}{\mathrm{A}_{\mathrm{it}-1}}\right)+v_{\mathrm{it}}$, where $A_{\mathrm{it}-1}$ is the total assets of companies in period $\mathrm{t}-1, \Delta \mathrm{REV}_{\mathrm{it}}$ is the difference in the revenues between period $\mathrm{t}$ and period $\mathrm{t}-1, \triangle \mathrm{REC}_{\mathrm{it}}$ is the difference in the net receivables between period $\mathrm{t}$ and period $\mathrm{t}-1$, and $\mathrm{PPE}_{\mathrm{it}}$ is the gross property plant and equipment in period $\mathrm{t}$ (see Dechow et al. 1995). 
Table 1 Number of winners and losers in the native contrarian portfolios and artificial momentum portfolios in the combined Shanghai and Shenzhen stock market

\begin{tabular}{|c|c|c|c|c|}
\hline \multirow[t]{2}{*}{ Date } & \multicolumn{2}{|l|}{ Winners } & \multicolumn{2}{|l|}{ Losers } \\
\hline & Native contrarian & Artificial momentum & Native contrarian & Artificial momentum \\
\hline Dec-06 & 50 & 48 & 53 & 3 \\
\hline Jan-07 & 48 & 45 & 52 & 0 \\
\hline Feb-07 & 52 & 50 & 48 & 2 \\
\hline Mar-07 & 53 & 35 & 47 & 18 \\
\hline Apr-07 & 53 & 10 & 46 & 24 \\
\hline May-07 & 55 & 44 & 46 & 6 \\
\hline Jun-07 & 54 & 15 & 43 & 12 \\
\hline Jul-07 & 51 & 9 & 47 & 19 \\
\hline Aug-07 & 48 & 4 & 45 & 37 \\
\hline Sep-07 & 48 & 6 & 49 & 41 \\
\hline Oct-07 & 43 & 5 & 51 & 39 \\
\hline Nov-07 & 48 & 3 & 51 & 51 \\
\hline Dec-07 & 49 & 3 & 48 & 47 \\
\hline Jan-08 & 50 & 0 & 48 & 48 \\
\hline Feb-08 & 52 & 1 & 50 & 50 \\
\hline Mar-08 & 52 & 0 & 49 & 49 \\
\hline Apr-08 & 55 & 1 & 43 & 43 \\
\hline May-08 & 52 & 2 & 37 & 34 \\
\hline Jun-08 & 54 & 2 & 45 & 39 \\
\hline Jul-08 & 51 & 24 & 41 & 11 \\
\hline Aug-08 & 52 & 44 & 38 & 0 \\
\hline Sep-08 & 54 & 52 & 47 & 0 \\
\hline Oct-08 & 44 & 39 & 50 & 2 \\
\hline Nov-08 & 50 & 45 & 38 & 2 \\
\hline Dec-08 & 50 & 42 & 48 & 3 \\
\hline Jan-09 & 46 & 39 & 49 & 4 \\
\hline Feb-09 & 45 & 27 & 46 & 16 \\
\hline Mar-09 & 47 & 29 & 43 & 10 \\
\hline Apr-09 & 53 & 40 & 47 & 1 \\
\hline May-09 & 57 & 49 & 48 & 3 \\
\hline Jun-09 & 60 & 24 & 46 & 11 \\
\hline Jul-09 & 58 & 54 & 51 & 1 \\
\hline Aug-09 & 60 & 54 & 47 & 2 \\
\hline Sep-09 & 60 & 26 & 49 & 17 \\
\hline Oct-09 & 58 & 13 & 49 & 35 \\
\hline Nov-09 & 57 & 6 & 47 & 45 \\
\hline Dec-09 & 59 & 18 & 51 & 43 \\
\hline Jan-10 & 57 & 22 & 50 & 42 \\
\hline
\end{tabular}


Table 1 continued

\begin{tabular}{|c|c|c|c|c|}
\hline \multirow[t]{2}{*}{ Date } & \multicolumn{2}{|l|}{ Winners } & \multicolumn{2}{|l|}{ Losers } \\
\hline & Native contrarian & Artificial momentum & Native contrarian & Artificial momentum \\
\hline Feb-10 & 56 & 21 & 47 & 40 \\
\hline Mar-10 & 55 & 34 & 54 & 23 \\
\hline Apr-10 & 56 & 42 & 52 & 14 \\
\hline May-10 & 58 & 54 & 45 & 4 \\
\hline Jun-10 & 68 & 49 & 56 & 22 \\
\hline Jul-10 & 67 & 44 & 54 & 22 \\
\hline Aug-10 & 73 & 33 & 53 & 17 \\
\hline Sep-10 & 65 & 13 & 57 & 39 \\
\hline Oct-10 & 69 & 12 & 54 & 41 \\
\hline Nov-10 & 68 & 14 & 52 & 34 \\
\hline Dec-10 & 78 & 31 & 61 & 37 \\
\hline Jan-11 & 69 & 7 & 65 & 55 \\
\hline Feb-11 & 70 & 1 & 74 & 69 \\
\hline Mar-11 & 75 & 9 & 59 & 51 \\
\hline Apr-11 & 75 & 6 & 60 & 43 \\
\hline May-11 & 78 & 1 & 55 & 53 \\
\hline Jun-11 & 73 & 2 & 53 & 48 \\
\hline Jul-11 & 81 & 6 & 55 & 47 \\
\hline Aug-11 & 73 & 13 & 62 & 51 \\
\hline Sep-11 & 71 & 21 & 61 & 40 \\
\hline Oct-11 & 64 & 21 & 64 & 40 \\
\hline Nov-11 & 58 & 31 & 66 & 34 \\
\hline Dec-11 & 51 & 17 & 75 & 65 \\
\hline Jan-12 & 55 & 5 & 68 & 60 \\
\hline Feb-12 & 59 & 15 & 68 & 49 \\
\hline Mar-12 & 64 & 9 & 62 & 54 \\
\hline
\end{tabular}

\subsection{Transparency Tests}

The winners and losers in the momentum portfolios have equal weights, and we can respectively observe their transparencies. As seen in the previous tables and discussions, the group of artificial winners is a subgroup of the original group of winners in the native contrarian portfolio. Therefore, the transparency indices of each share in the contrarian portfolio are computable.

All the shares in our tests have the transparency indices shown in Fig. 12. The level of the winner's transparency in the native contrarian portfolio is similar to that of the artificial momentum winners. We categorize the stocks into 3 groups according to their transparency conditions and data availability: $W_{m} \supseteq W_{c}^{t p} \supseteq W_{a}^{t p}$, where $W_{m}$ represents the winners in the native momentum portfolio, $W_{c}^{t p}$ represents the winners in the normal momentum portfolio with transparency indices, and $W_{a}^{t p}$ represents the stocks that have positive profits at $h=6$ and is a subset of $W_{c}^{t p}$. 


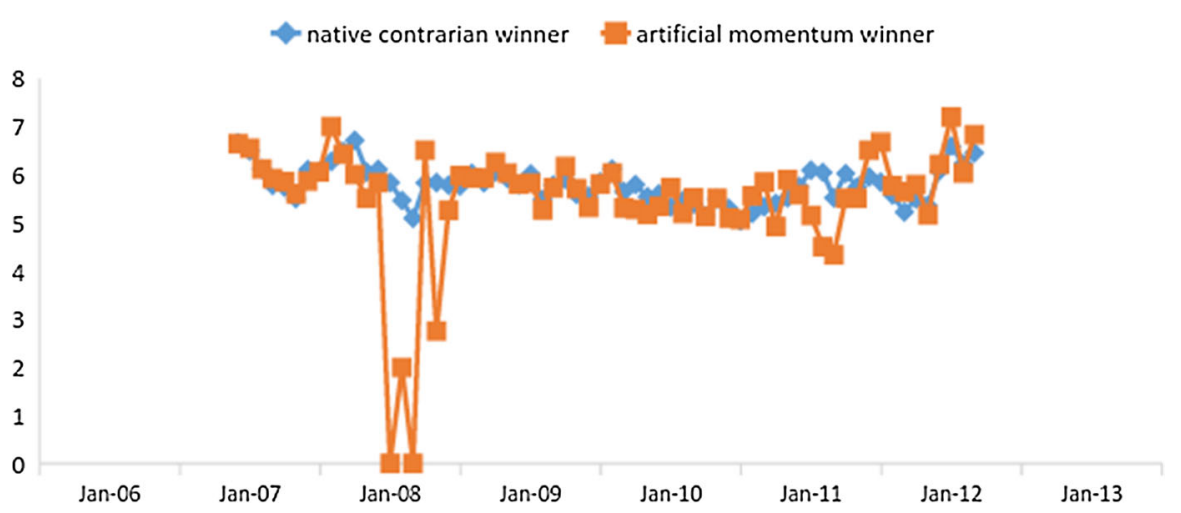

Fig. 12 Transparencies of the native contrarian winners and artificial momentum winners in the ShanghaiShenzhen stock markets (Y-axis) and the timing of winner selection (X-axis)

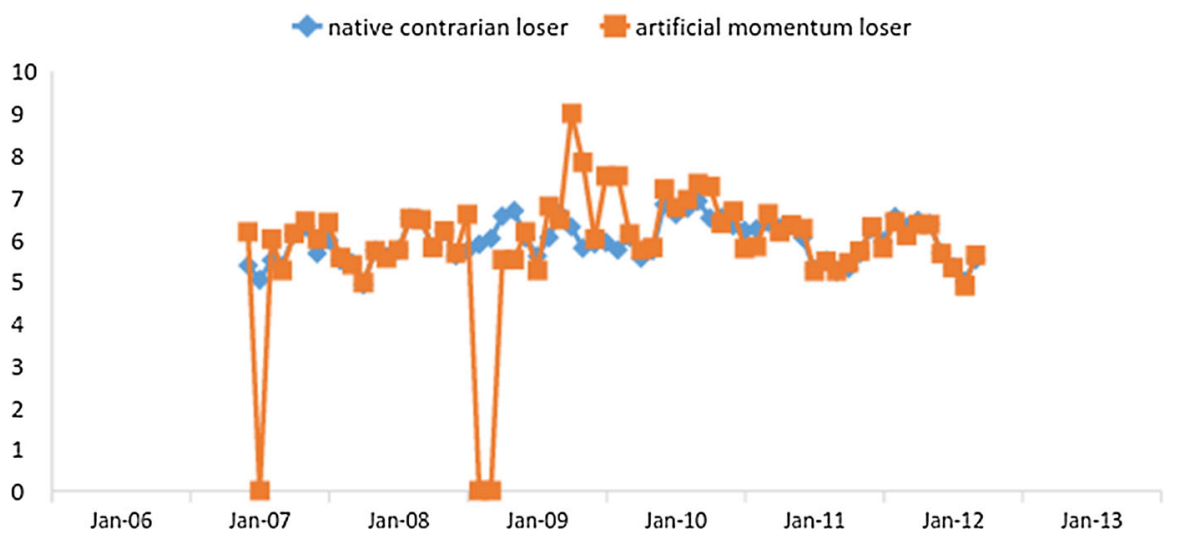

Fig. 13 Transparencies of the native contrarian and artificial momentum losers in the Shanghai-Shenzhen stock markets (Y-axis) and the timing of loser decisions (X-axis)

Zero transparency exists in two periods as shown in Fig. 12, because all stock prices of the native contrarian losers exhibit a reversal at $h=6$. These paths in Fig. 12 are similar. The logic underlying the analysis in relation to the loser's transparency is the same as the winner's transparency. The transparency paths between the artificial momentum losers and native contrarian losers are close to each other as shown in Fig. 13.

We also tested the Shanghai market, the Shenzhen market, the combination of Ashares for Shanghai-Shenzhen, the combination of B-shares for Shanghai-Shenzhen, the Shanghai A-share market, the Shanghai B-share market, the Shenzhen A-share market and the Shenzhen B-share market. Their results are not different from those for the overall market. To simplify this paper, we show them in "Appendix B".

The degrees of transparency of the winners are higher than those of the losers. In addition, we know that the transparencies between the contrarian and momentum portfolios are similar to each other. Their levels of transparency are close to the average, and the difference in transparency cannot be explained by the significant contrarian profits in China. 
Extremely high or extremely low transparency does not occur in any of the 84 momentum or contrarian portfolios, and most of the transparency indices are close to the mean value of 5.5. These outputs imply that a share with extreme transparency has a small probability of price reversal or inertia.

\subsection{Robustness Check}

Other tests that are not listed here (Shanghai A-shares, Shanghai B-shares, Shenzhen A-shares and Shenzhen B-shares) have many periods without artificial momentum winners or losers. If the market has no artificial momentum-winner or momentumloser, then we infer that there is no continuity in the price trends, which means that the contrarian strategy in China is not easy to change (see "Appendix B").

\section{Conclusions}

Our research shows that negative momentum profits exist in the Chinese stock market. To confirm this result, we ran tests on nine combinations of datasets: (a) Shanghai A-shares, (b) Shenzhen A-shares, (c) Shanghai B-shares, (d) Shenzhen B-shares, (e) a combination of both the Shanghai and Shenzhen stock markets, (f) a combination of A-shares in the Shanghai and Shenzhen stock markets, (g) a combination of Bshares in the Shanghai and Shenzhen stock markets, (h) the Shanghai stock market, and (i) the Shenzhen stock market. These tests have consistent outcomes and provide evidence that the world's second-largest stock market has a significant price overreaction. Momentum profits in the Shanghai and Shenzhen markets are almost negative, which is significantly different from the results of past studies on the US or European markets.

In the last twenty years, China's economy has grown significantly. However, the institution lacks the mechanism to expose the financial status of almost all listed companies. The companies do not have the incentive to disclose their real statements because the financial regulations are incomplete. This study reveals an insignificant correlation between the reversal of stock prices and financial transparency. In cases of both artificial inertia and native reversal, the listed corporations in China do not have complete transparency.

Our outcome regarding transparency echoes the results of Kang et al. (2002). Stock price overreactions are due to the dominance of individual investors. These retail investors lack credible information about listed companies and rely on market rumors. The "cooked" financial statements have little effect on the trends in stock prices in the Shanghai and Shenzhen markets.

"Backdoor listings" in China's stock markets are frequent. Mergers and acquisitions can cause the prices of losers to rise. Retail investors "vote with their feet" to settle the position of winner shares and cause their prices to go down. These could be the reasons for the price reversal and are left to future research.

Open Access This article is distributed under the terms of the Creative Commons Attribution 4.0 International License (http://creativecommons.org/licenses/by/4.0/), which permits unrestricted use, distribution, 
and reproduction in any medium, provided you give appropriate credit to the original author(s) and the source, provide a link to the Creative Commons license, and indicate if changes were made.

\section{Appendix A}

\section{f. A combination of A-shares in the Shanghai and Shenzhen stock markets}

We merge A-shares in the Shanghai and Shenzhen stock markets into a subsample. The momentum profits of the overall A-shares are computed and compared with those of the overall B-shares in the next section. Increasing the length of the formation period makes the contrarian profit more evident in a given holding period. With a longer period of observation, more information can be extracted, and the contrarian profits are enlarged. However, the A-shares of the Shanghai and Shenzhen markets still have price reversals even under the longer formation period (Figs. 14, 15).

\section{g. A combination of B-shares in the Shanghai and Shenzhen stock markets}

Before this test, we have observed that the B-shares in the Shenzhen and Shanghai stock markets individually have contrarian profits. When the B-shares in these two markets are combined, they still exhibit the contrarian property (Figs. 16, 17).

According to Fama and French (2012) and Griffin et al. (2003), the main nonRMB markets in North America and Europe have momentum profits. However, our research finds that Shanghai B-shares and Shenzhen B-shares individually result in contrarian profits. To test the robustness of the contrarian result and compare these markets with the other main markets, we combined these non-RMB B-share markets and still obtained a contrarian outcome.

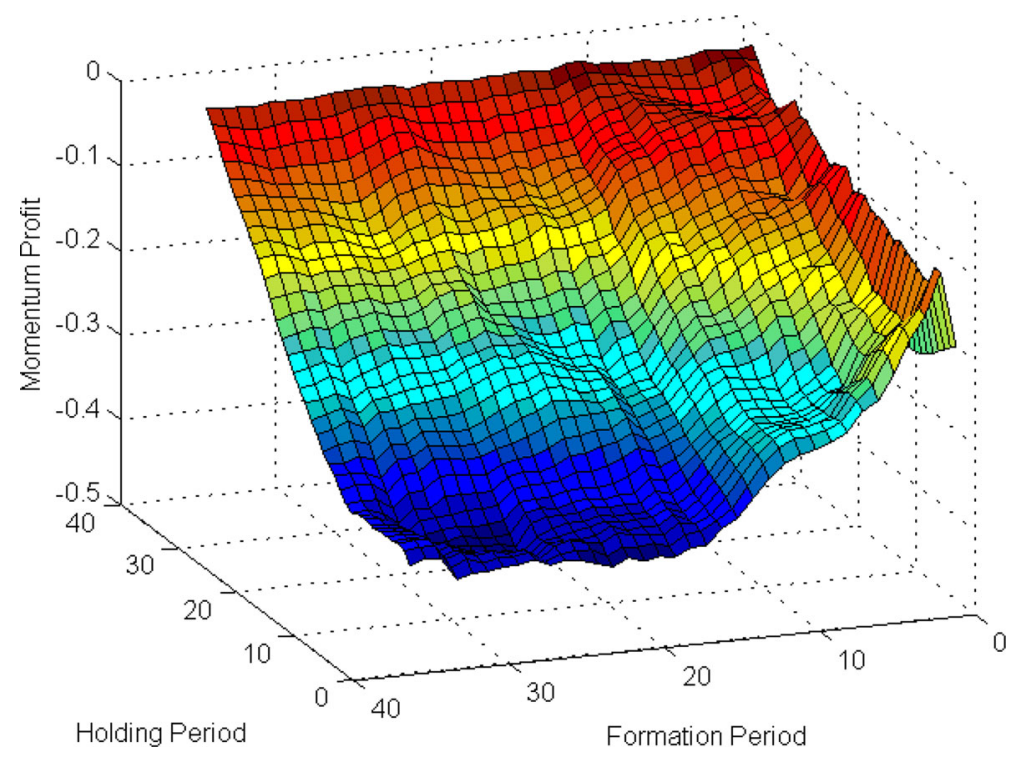

Fig. 14 Momentum profits of the combined A-shares in 2 dimensions with formation and holding periods of $36 \times 36$ months 




Fig. 15 Student $t$ values of the momentum profits in the combined A-shares in 2 dimensions with formation and holding periods of $36 \times 36$ months

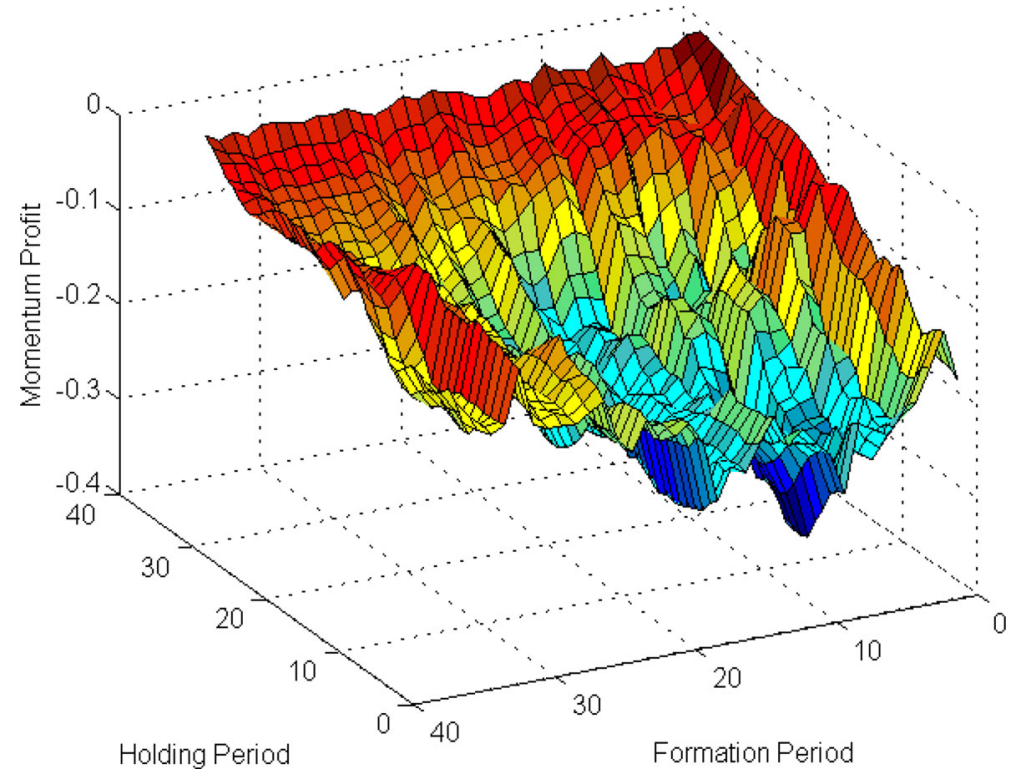

Fig. 16 The momentum profit of the combined B-shares in 2 dimensions with formation and holding periods of $36 \times 36$ months 


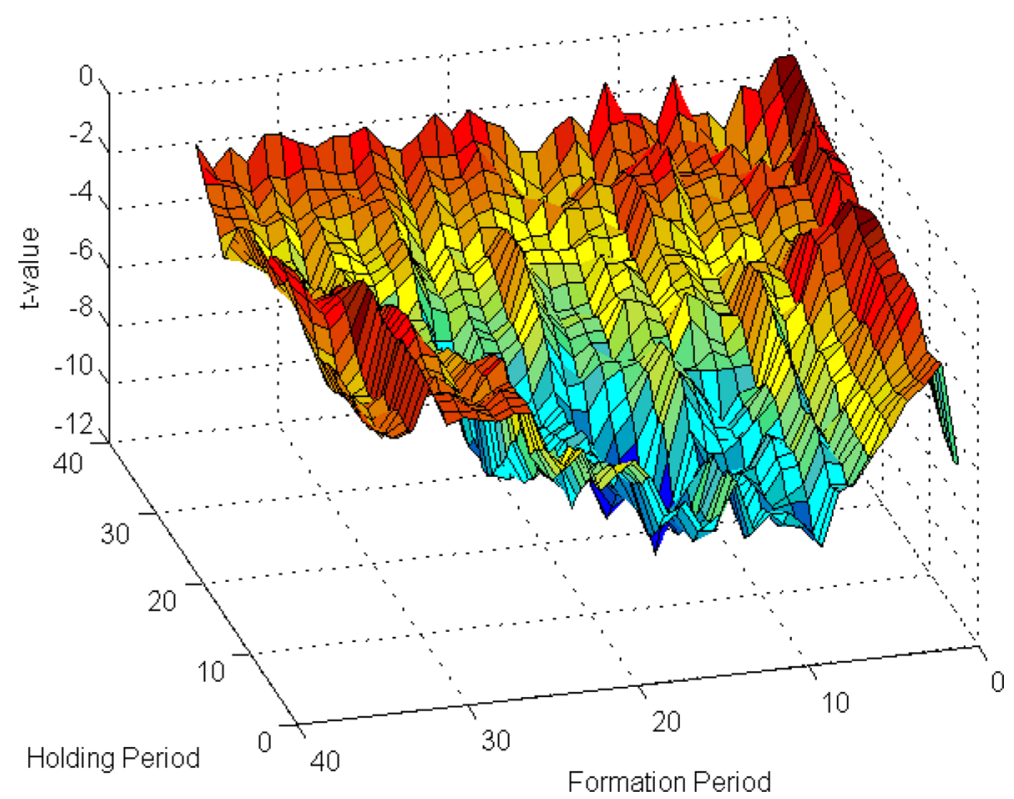

Fig. 17 Student $t$ values of the momentum profits in the combined B-shares in 2 dimensions with formation and holding periods of $36 \times 36$ months

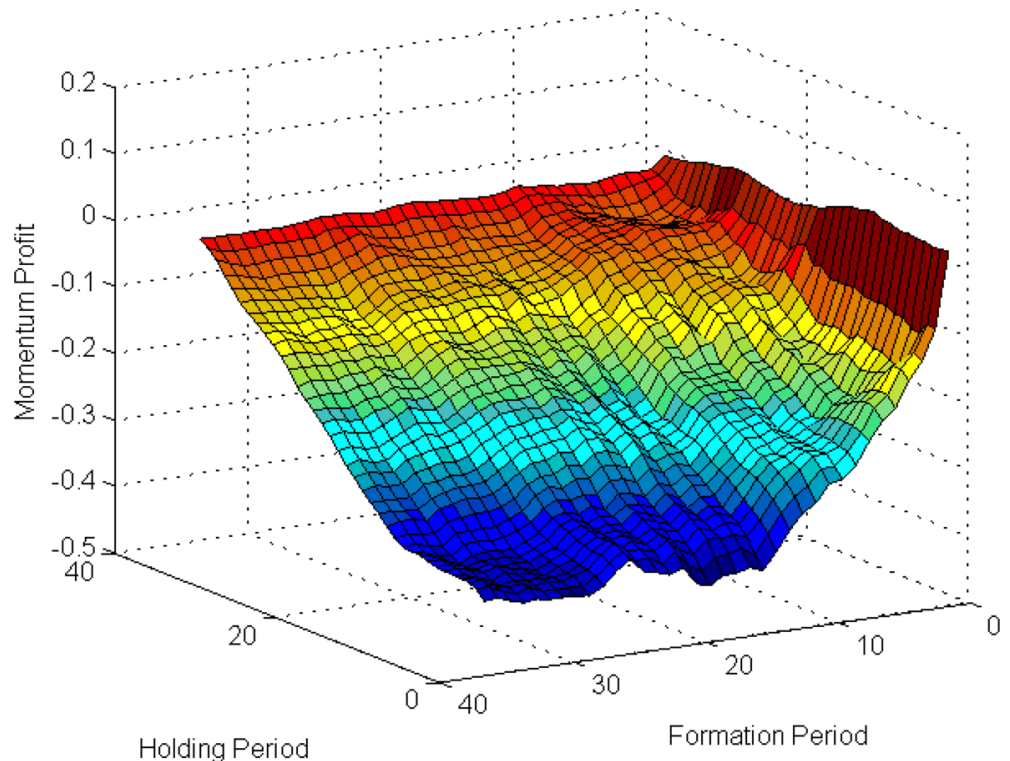

Fig. 18 Momentum profits of the Shanghai stock markets in 2 dimensions with formation and holding periods of $36 \times 36$ months 


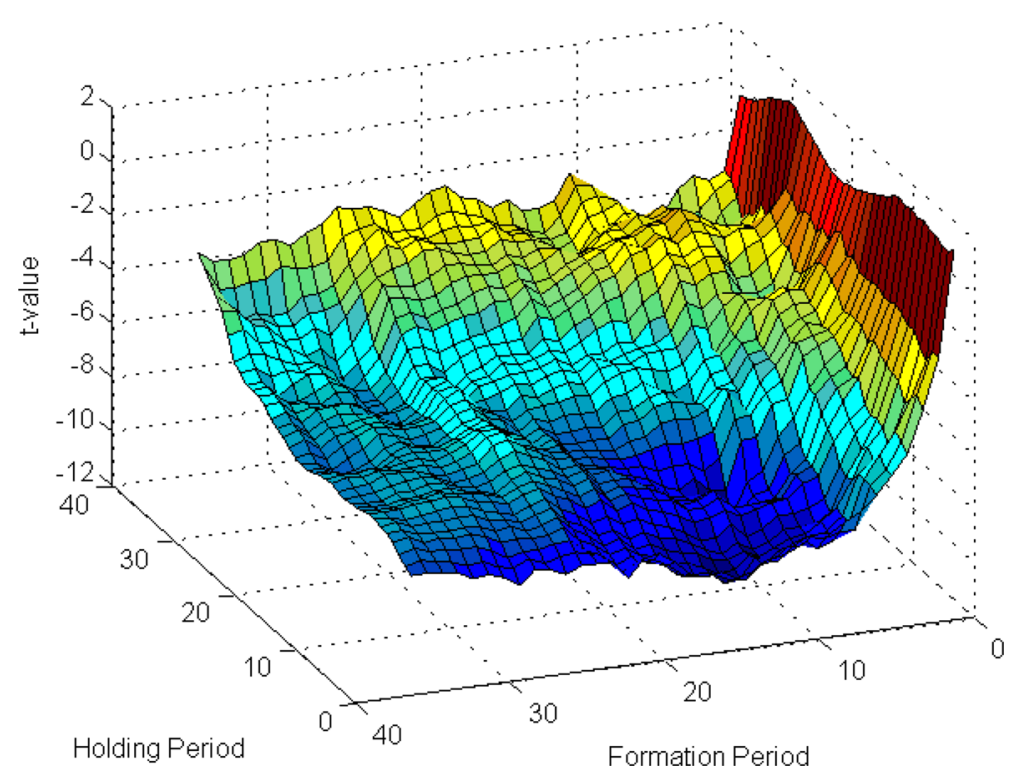

Fig. 19 Student $t$ values of the momentum profits in the Shanghai stock markets in 2 dimensions with formation and holding periods of $36 \times 36$ months

\section{h. Shanghai stock market}

Figure 18 shows that a negative momentum profit significantly exists between the 2nd and 36th formation periods. The momentum profit in the first period $(f=1)$ in the Shanghai stock market does not violate the trend during the extended formation period. Figure 18 tells us that the Shanghai stock market has a momentum intensity at the beginning of the holding period and has contrarian profits after investing after a 2-month holding period (Fig. 19).

\section{i. Shenzhen stock market}

According to Fig. 20, we know that the Shenzhen stock market has a significant contrarian profit with a shorter formation period. The phenomenon of price reversal still shows that strategies that short the quintile winner and long the quintile loser give rise to profits (Fig. 21).

\section{Appendix B}

a. Shanghai stock market

See Figs. 22, 23.

b. Shenzhen stock market

See Figs. 24, 25.

c. Combination of A-shares in the Shanghai and Shenzhen stock markets 


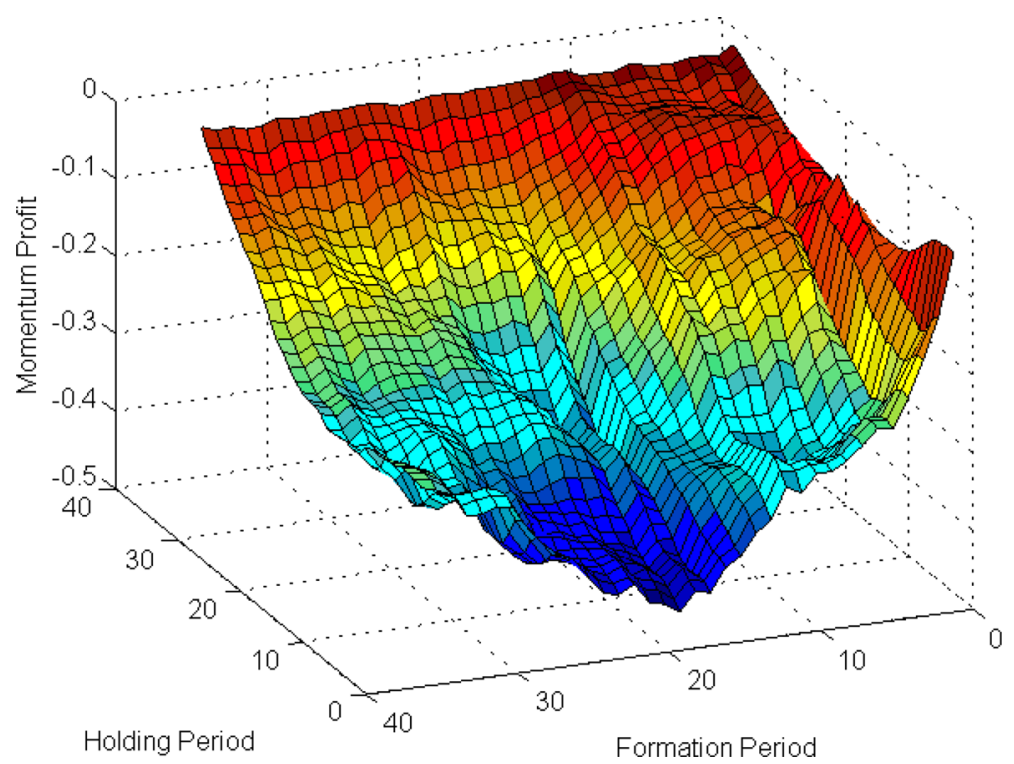

Fig. 20 Momentum profits of the Shenzhen stock markets in 2 dimensions with formation and holding periods of $36 \times 36$ months

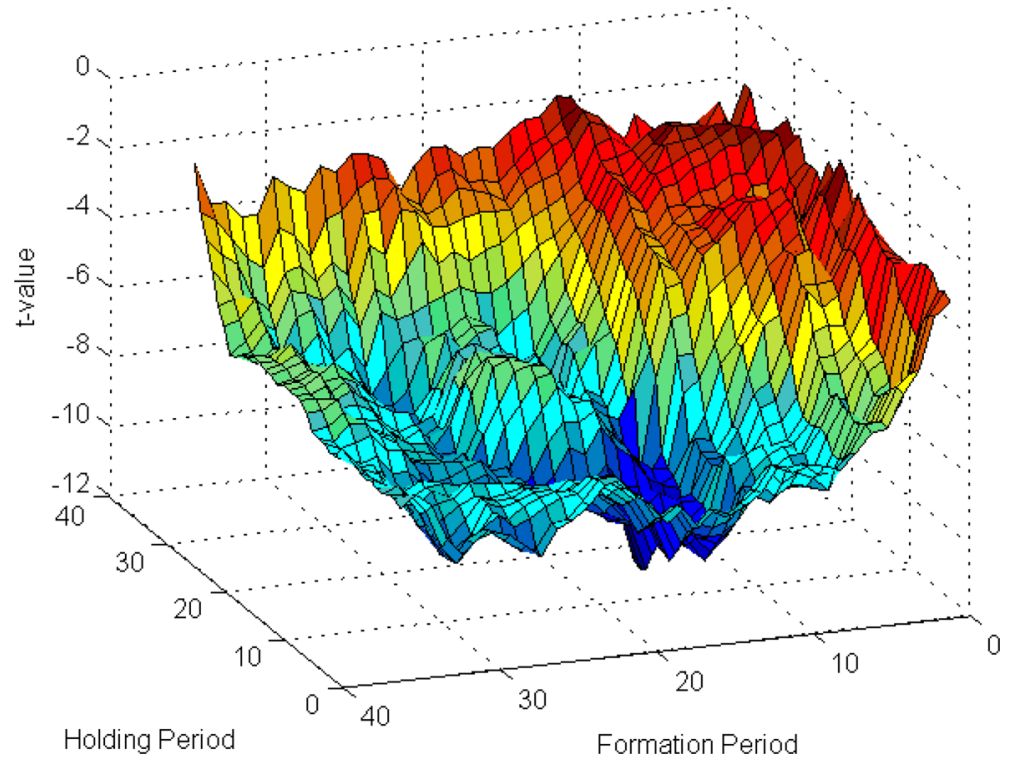

Fig. 21 Student $t$ values of the momentum profits in the Shenzhen stock markets in 2 dimensions with formation and holding periods of $36 \times 36$ months 


\section{native contrarian winner artificial momentum winner}

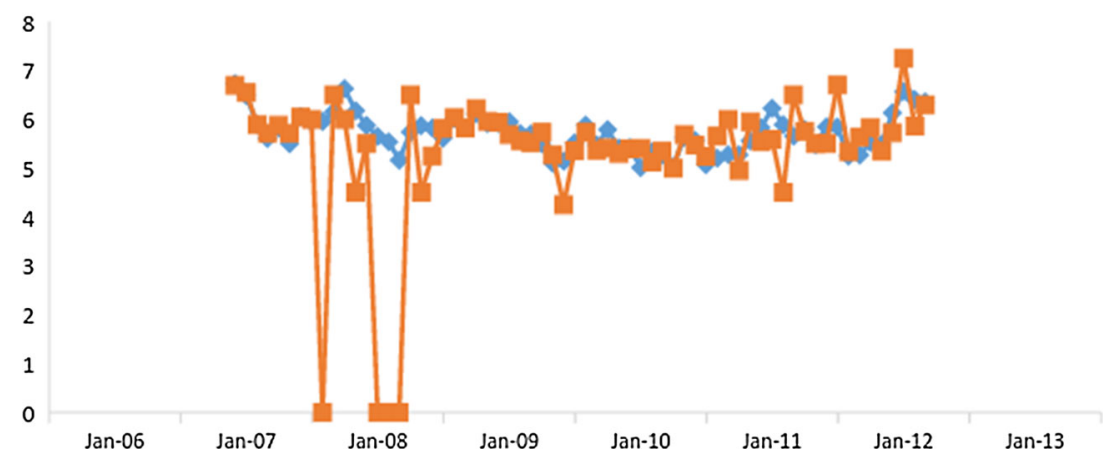

Fig. 22 Transparencies of the native contrarian and artificial momentum winners in the Shanghai stock market (Y-axis) and timing of winner selections (X-axis)

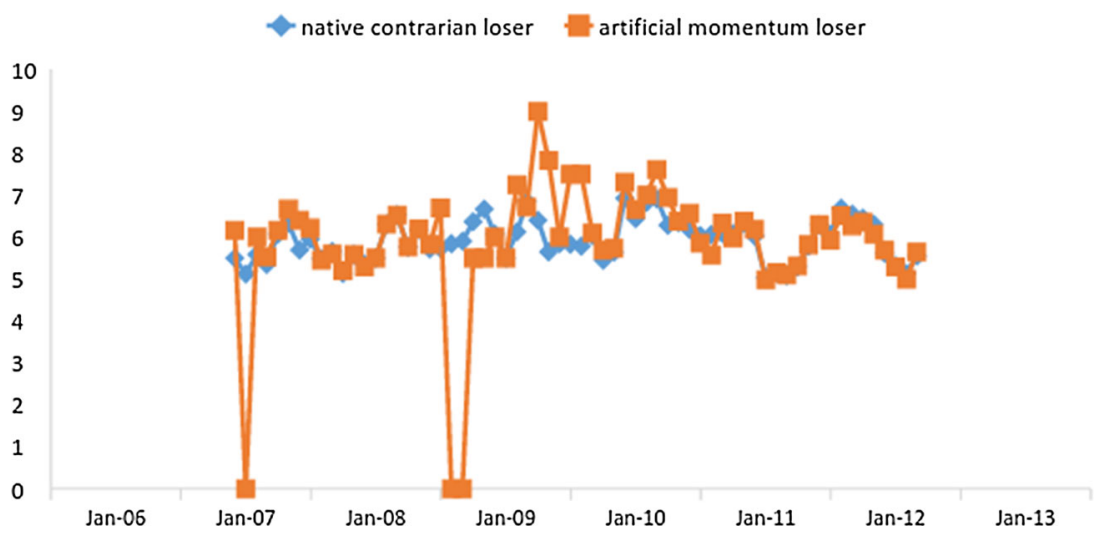

Fig. 23 Transparencies of the native contrarian and artificial momentum losers in the Shanghai stock market (Y-axis) and timing of the loser decisions (X-axis)



Fig. 24 Transparencies of the native contrarian and artificial momentum winners in the Shenzhen stock market (Y-axis) and timing of the winner selections (X-axis) 


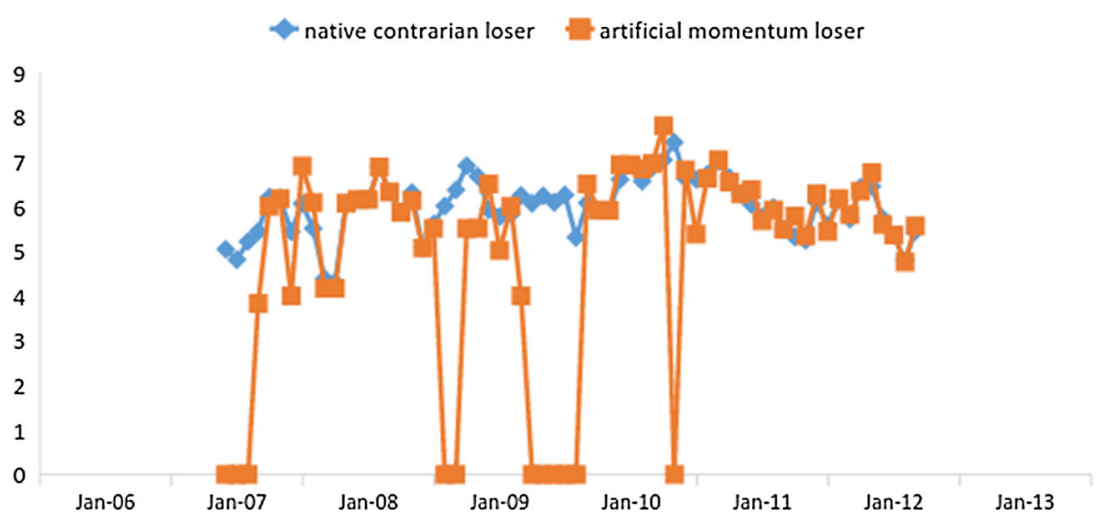

Fig. 25 Transparencies of the native contrarian and artificial momentum losers in the Shenzhen stock market (Y-axis) and timing of the loser decisions (X-axis)

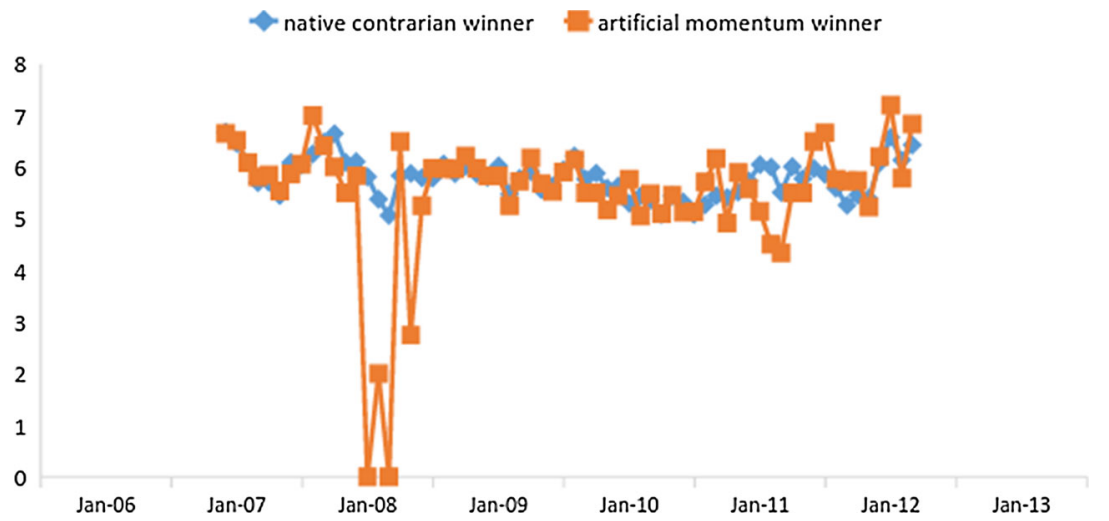

Fig. 26 Transparencies of the native contrarian and artificial momentum winners in the combined Shanghai and Shenzhen A-share markets (Y-axis) and timing of the winner selections (X-axis)

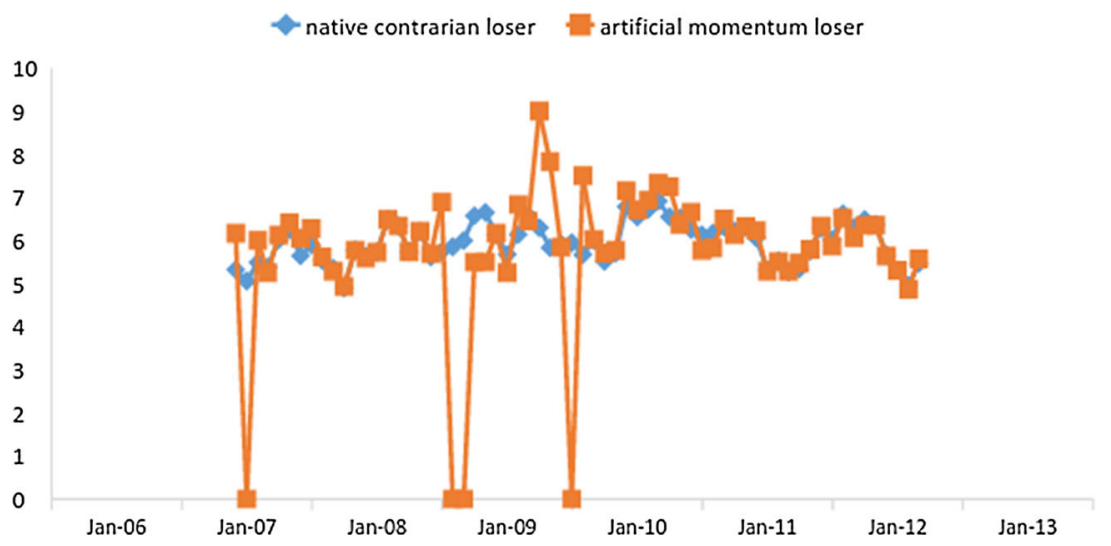

Fig. 27 Transparencies of the native contrarian and artificial momentum losers in the combined Shanghai and Shenzhen A-Share markets (Y-axis) and timing of the loser decisions (X-axis) 


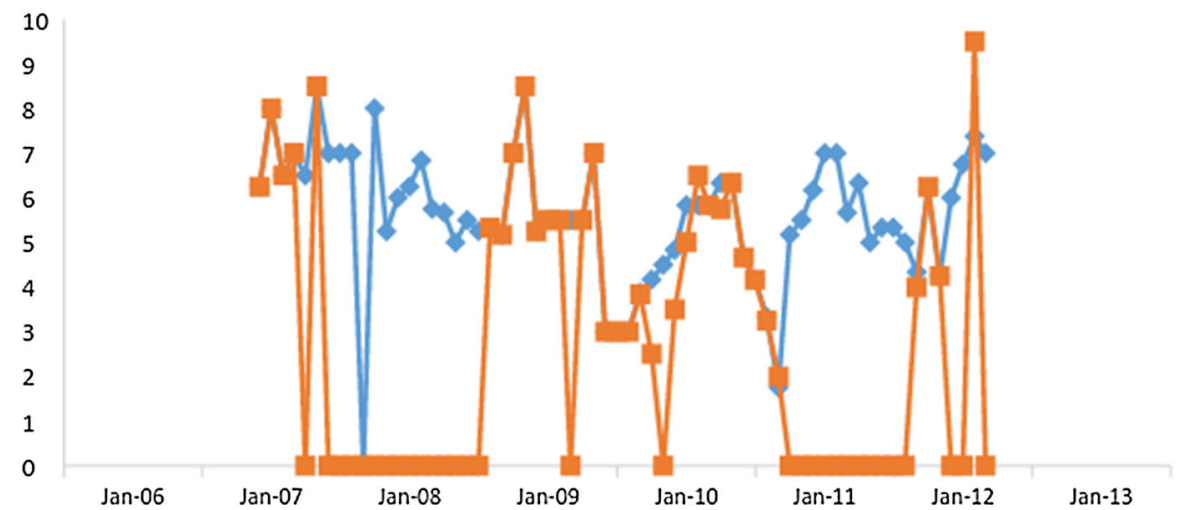

Fig. 28 Transparencies of the native contrarian and artificial momentum winners in the combined Shanghai and Shenzhen B-share markets (Y-axis) and timing of the winner selections (X-axis)

native contrarian loser $\quad$ artificial momentum loser

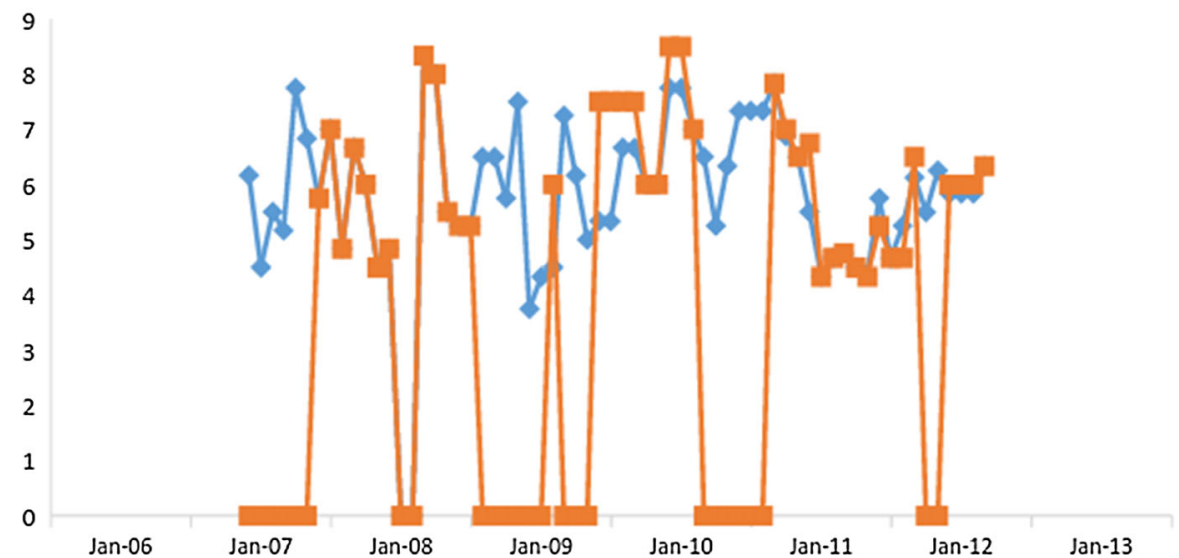

Fig. 29 Transparencies of the native contrarian and artificial momentum losers in the combined Shanghai and Shenzhen B-share markets (Y-axis) and timing of the loser decisions (X-axis)

See Figs. 26, 27.

d. Combination of B-shares in the Shanghai and Shenzhen stock markets

See Figs. 28, 29.

e. A-shares of the Shanghai stock market

See Figs. 30, 31.

f. B-shares of the Shanghai stock market

See Figs. 32, 33.

g. A-shares of the Shenzhen stock market 


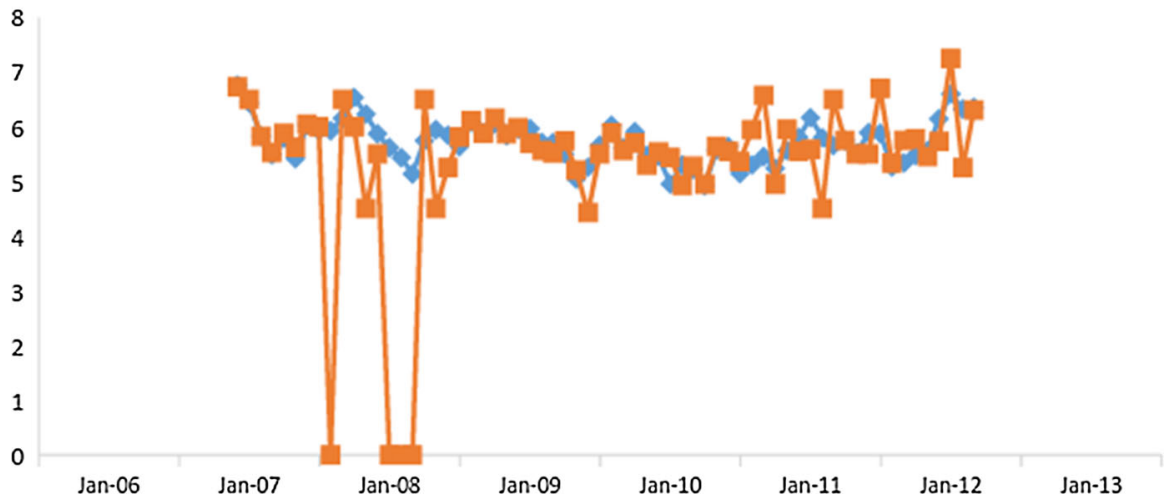

Fig. 30 Transparencies of the native contrarian and artificial momentum winners in the Shanghai A-share stock market (Y-axis) and timing of the winner selections (X-axis)



Fig. 31 Transparencies of the native contrarian and artificial momentum losers in the Shanghai A-share stock market (Y-axis) and timing of the loser decisions (X-axis)

See Figs. 34, 35.

h. B-shares of the Shenzhen stock market

See Figs. 36, 37. 


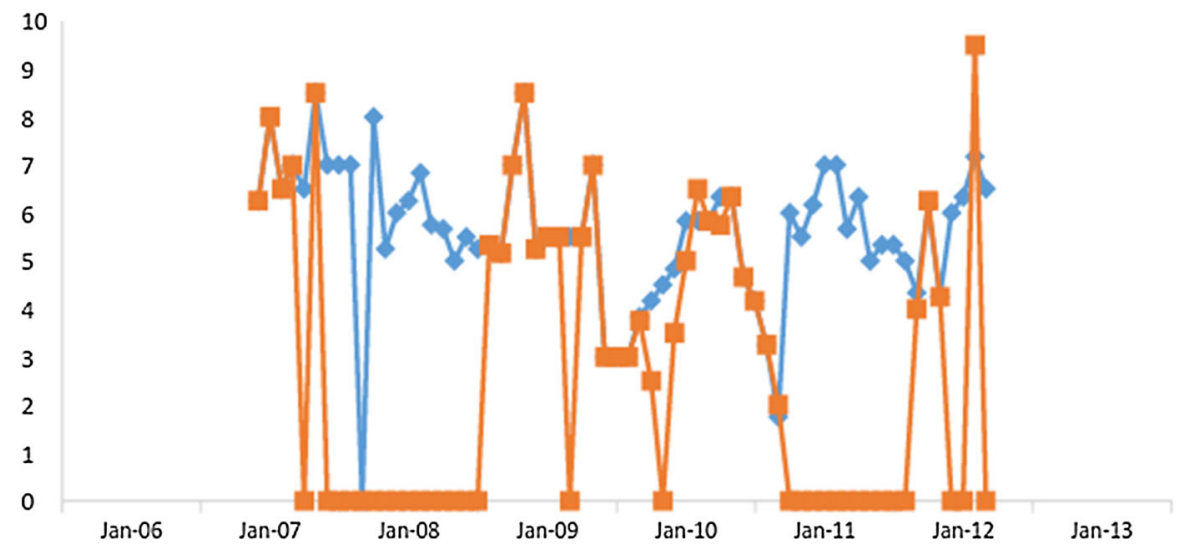

Fig. 32 Transparencies of the native contrarian and artificial momentum winners in the Shanghai B-share market (Y-axis) and timing of winner selections (X-axis)

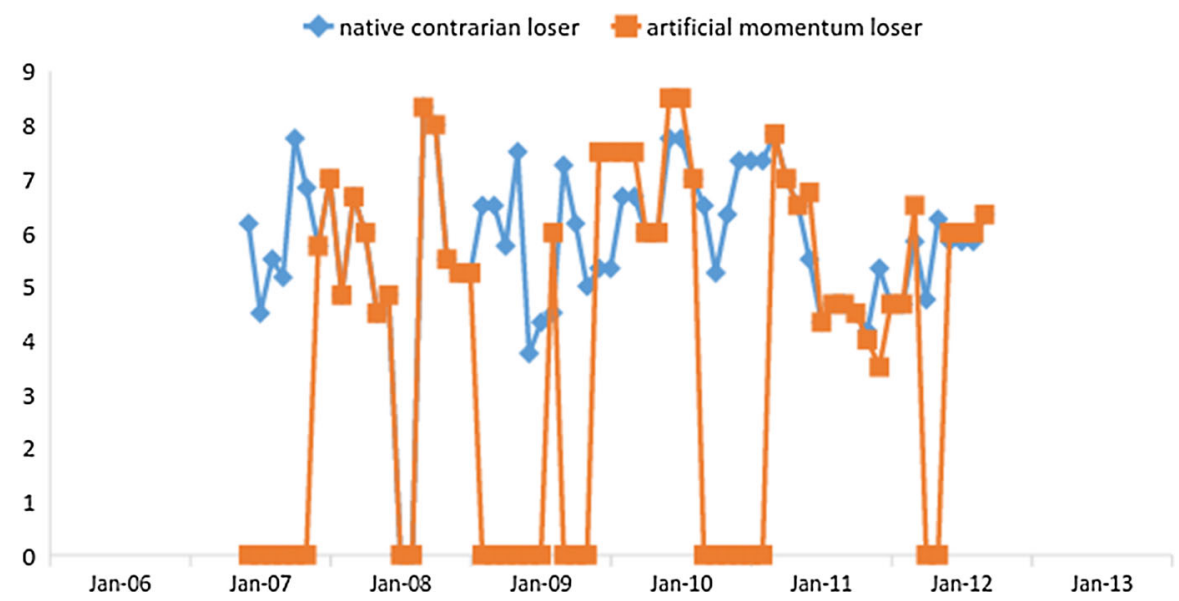

Fig. 33 Transparencies of the native contrarian and artificial momentum losers in the Shanghai B-share market (Y-axis) and timing of the loser decisions (X-axis) 


\section{$\sim$ native contrarian winner $\quad$ artificial momentum winner}

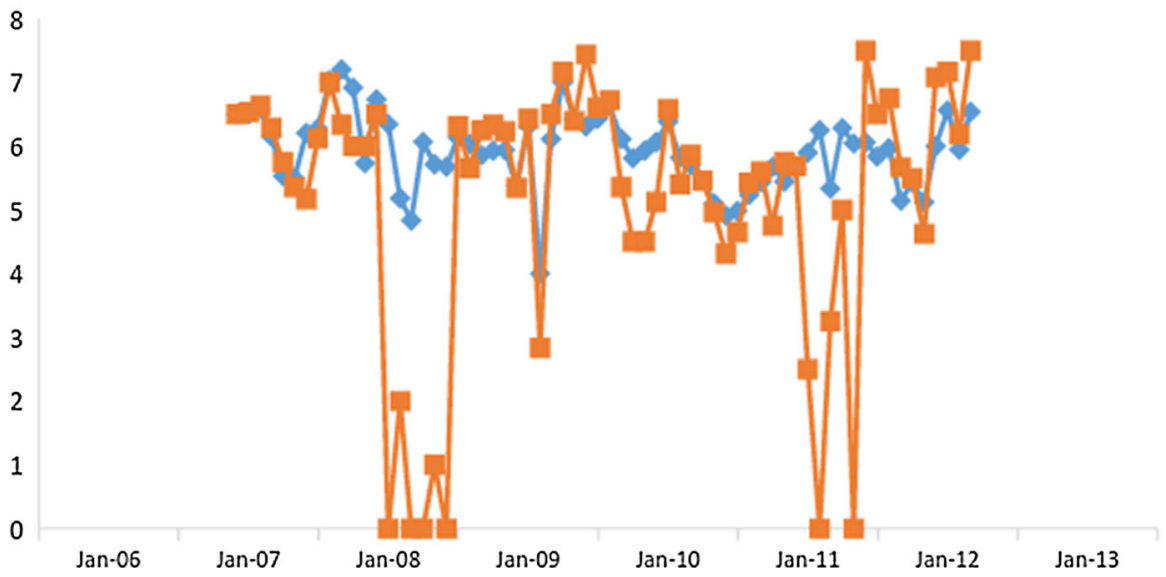

Fig. 34 Transparencies of the native contrarian and artificial momentum winners in the Shenzhen A-share market (Y-axis) and timing of the winner selections (X-axis)



Fig. 35 Transparencies of the native contrarian and artificial momentum losers in the Shenzhen A-share market (Y-axis) and timing of loser decisions (X-axis) 


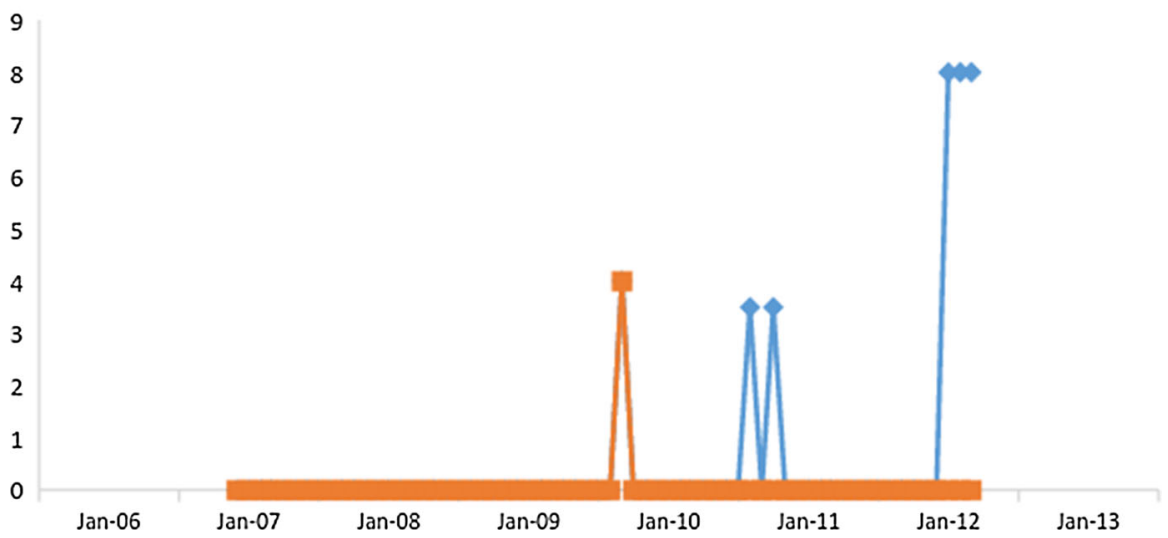

Fig. 36 Transparencies of the native contrarian and artificial momentum winners in the Shenzhen B-share market (Y-axis) and timing of the winner selections (X-axis)

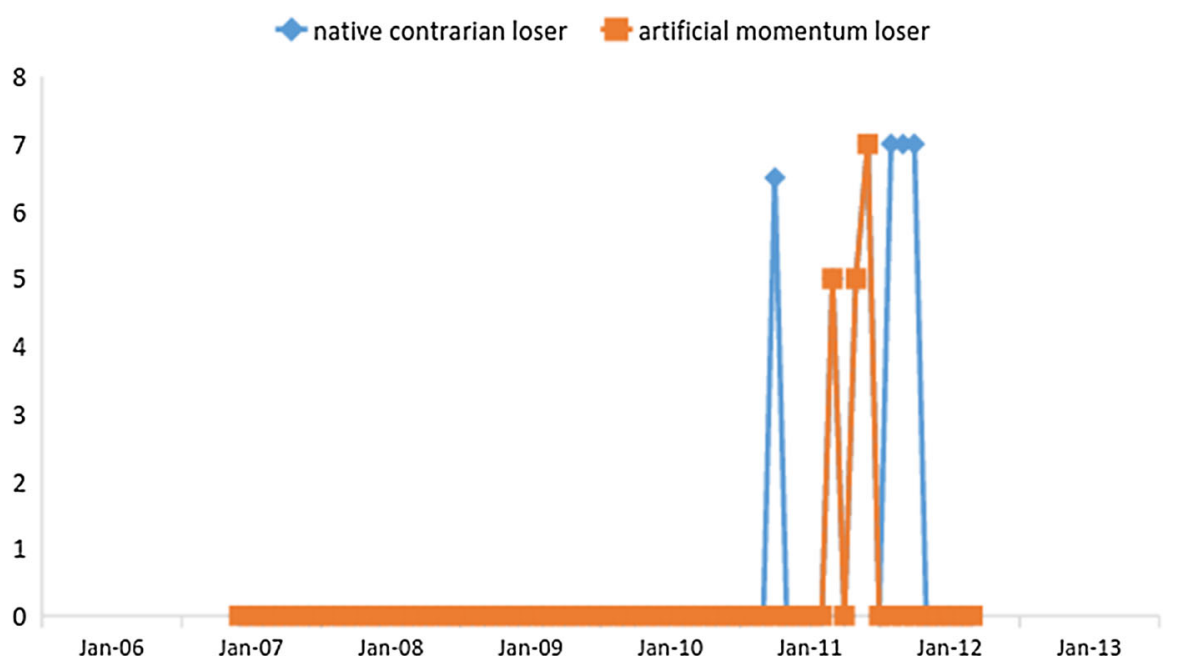

Fig. 37 Transparencies of the native contrarian and artificial momentum losers in the Shenzhen B-share market (Y-axis) and timing of loser decisions (X-axis)

\section{References}

Asness, C. S., Moskowitz, T. J., \& Pedersen, L. H. (2013). Value and momentum everywhere. Journal of Finance, 68, 929-985.

Avramov, D., Chordia, T., Jostova, G., \& Philipov, A. (2007). Momentum and credit rating. Journal of Finance, 62, 2503-2520.

Barucci, E., Monte, R., \& Renò, R. (2004). Asset price anomalies under bounded rationality. Computational Economics, 23, 255-269.

Bhattacharya, U., Daouk, H., \& Welker, M. (2003). The world price of earnings opacity. Accounting Review, 78, 641-678.

Chan, L. K. C., Jegadeesh, N., \& Lakonishok, J. (1996). Momentum strategies. Journal of Finance, 51, $1681-1713$. 
Chordia, T., \& Shivakumar, L. (2002). Momentum, business cycle and time-varying expected returns. Journal of Finance, 57, 985-1019.

Chui, A. C., Titman, S., \& Wei, K. J. (2010). Individualism and momentum around the world. Journal of Finance, 65, 361-392.

Cooper, M. J., Gutierrez, J. R., \& Hameed, A. (2004). Market states and momentum. Journal of Finance, 59, 1345-1365.

Dechow, P. M., Sloan, R. G., \& Sweeney, R. G. (1995). Detecting earnings management. Accounting Review, 70, 193-225.

Fama, E. F., \& French, K. R. (2012). Size, value, and momentum in international stock returns. Journal of Financial Economics, 105, 457-472.

Garlappi, L., \& Yan, H. (2011). Financial distress and the cross-section of equity returns. Journal of Finance, 66, 789-822.

Griffin, J. M., Ji, S., \& Martin, J. S. (2003). Momentum investing and business cycle risk: Evidence from pole to pole. Journal of Finance, 58, 2515-2547.

Hillert, A., Jacobs, H., \& Muller, S. (2014). Media makes momentum. Review of Financial Studies, 27, 3467-3501.

Hong, H., Lim, T., \& Stein, J. C. (2000). Bad news travels slowly: Size, analyst coverage, and the profitability of momentum strategies. Journal of Finance, 55, 265-295.

Jegadeesh, N., \& Titman, S. (1993). Returns to buying winners and selling losers: Implications for stock market efficiency. Journal of Finance, 48, 65-91.

Jiang, Y., \& Bao, W. (2015). The momentum effect in China stock market. In Proceedings of the 2015 12th international conference on service systems and service management (ICSSSM).

Jiang, Z. (2012). Momentum and contrarian strategies in the Chinese stock market, working paper (Master Thesis).

Kang, J., Liu, M.-H., \& Ni, S. X. (2002). Contrarian and momentum strategies in the China stock market: 1993-2000. Pacific-Basin Finance Journal, 10, 243-265.

Lee, C. M. C., \& Swaminathan, B. (2000). Price momentum and trading volume. Journal of Finance, 55, 2017-2069.

Lin, H-W., Xiao, H., \& Zhang, N. (2015). China momentum and transparency. In Proceedings of 2015 3 rd global economy and governance-Challenges of environmental finance, social responsibility and governance (2015 GEG).

Moskowitz, T. J., \& Grinblatt, M. (1999). Do industries explain momentum? Journal of Finance, 54, 12491290.

Naughton, T., Truong, C., \& Veeraraghavan, M. (2008). Momentum strategies and stock returns: Chinese evidence. Pacific-Basin Finance Journal, 16, 476-492.

$\mathrm{Su}, \mathrm{D}$. W. (2011). An empirical analysis of industry momentum in Chinese stock markets. Emerging Markets Finance and Trade, 47, 4-27.

$\mathrm{Wu}$, Y. (2011). Momentum trading, mean reversal and overreaction in Chinese stock market. Review of Quantitative Finance and Accounting, 37, 301-323. 